\title{
Catalyst activity or stability: the dilemma in Pd-catalyzed polyketone synthesis
}

Francesco Amoroso ${ }^{a, b}$ Ennio Zangrando, ${ }^{a}$ Carla Carfagna, ${ }^{c}$ Christian Müller, ${ }^{d}$ Dieter Vogt,${ }^{e}$ Mohamed Hagar, ${ }^{f}$ Fabio Ragaini, ${ }^{* g}$ and Barbara Milani ${ }^{* a}$

${ }^{a}$ Dipartimento di Scienze Chimiche e Farmaceutiche, Università di Trieste, Via Licio Giorgieri 1, 34127 Trieste, Italy. Fax: 39040 5583903; Tel: 39040 5583956; e-mail: milaniba@units.it

${ }^{b}$ Dipartimento di Chimica, Fisica e Ambiente, Università di Udine, Via del Cotonificio 108, 33100 Udine, Italy.Fax: 0432 558803; Tel: 0432 558755; e-mail: francesco.amoroso@uniud.it

${ }^{c}$ Dipartimento di Scienze Biomolecolari, Università di Urbino, Piazza Rinascimento 6, 61029 Urbino, Italy. Fax: 390722 303311; Tel: +390722 303312; e-mail: carla.carfagna@uniurb.it

${ }^{d}$ Institut für Chemie und Biochemie-Anorganische Chemie, Freie Universität Berlin, 14195 Berlin, Germany. Tel: +4930838 54004; e-mail: c.mueller@fu-berlin.de

${ }^{e}$ School of Chemistry, University of Edinburgh, Edinburgh EH9 3JJ, Scotland, UK. Tel: +44 131 651 7767; e-mail:d.vogt@ed.ac.uk

${ }^{f}$ Chemistry Department, Alexandria University, Ibrahimia, Alexandria 21321, Egypt.

${ }^{g}$ Dipartimento di Chimica, Università di Milano, Via C. Golgi 19, 20133 Milano, Italy; Fax: 02 50314405; Tel: 02 50314373; e-mail: fabio.ragaini@unimi.it.

Received (in $X X X, X X X) X$ th $X X X X X X X X X 20 X X$, Accepted Xth $X X X X X X X X X 20 X X$ DOI: $10.1039 / b 000000 x$

Keywords: $\alpha$-diimines; palladium; vinyl arene; copolymerization; polyketones; kinetic

\begin{abstract}
A series of Pd-complexes containing nonsymmetrical bis(aryl-imino)acenaphthene (Ar-BIAN) ligands, featured by substituents on the meta positions of the aryl rings, have been synthesized, characterized and applied in $\mathrm{CO} /$ vinyl arene copolymerization reactions. Crystal structures of two neutral Pd-complexes have been solved allowing comparison of the bonding properties of the ligand. Kinetic and mechanistic investigations on these complexes have been performed. The kinetic investigations indicate that in general ligands with electron-withdrawing substituents give more active, but less stable, catalytic systems, although steric effects also play a role. The good performance observed with nonsymmetrical ligands is at least in part due to a compromise between catalyst activity and lifetime, leading to a higher overall productivity with respect to catalysts based on their symmetrical counterparts. Additionally, careful analysis of the reaction profiles provided information on the catalyst deactivation pathway. The latter begins with the reduction of a $\operatorname{Pd}(\mathrm{II})$ Ar-BIAN complex to the corresponding $\operatorname{Pd}(0)$ species, a reaction that can be reverted by the action
\end{abstract}


of benzoquinone. Then the ligand is lost, a process that appears to be facilitated by the contemporary coordination of an olefin or a $\mathrm{CO}$ molecule. The so formed $\operatorname{Pd}(0)$ complex immediately reacts with another molecule of the initial $\mathrm{Pd}(\mathrm{II})$ complex to give a $\mathrm{Pd}(\mathrm{I})$ dimeric species that irreversibly evolves to metallic palladium. Mechanistic investigations performed on the complex with a nonsymmetrical Ar-BIAN probe evidence that the detected intermediates are featured by the Pd-C bond trans to the Pd-N bond of the aryl ring bearing electron-withdrawing substituents. In addition, the intermediate resulting from the insertion of 4-methylstyrene into the Pd-acyl bond is a five-member palladacycle and not the open-chain $\eta^{3}$-allylic species observed for complexes with Ar-BIANs substituted in ortho position.

\section{Introduction}

$\alpha$-Diimine ligands, having a 1,4-diaza-1,3-butadiene or an acenaphthene skeleton (Ar-BIAN) and aryl rings on the imine nitrogen atoms, are known since 1969. ${ }^{1}$ However, only in 1992 the first straightforward synthetic procedure was reported by Elsevier. ${ }^{2}$ Afterwards, the main application of these molecules as ancillary ligands in homogeneous catalysis was brought to the attention of a wider scientific community by Brookhart's discovery that the relevant nickel and palladium complexes generate extremely efficient catalysts for polyethylene synthesis. ${ }^{3}$ This finding had an impressive impact in the field of catalysis for polymerization resulting in a huge development of ligands of this family. ${ }^{4}$ The same palladium complexes also revealed to be able to catalyze the copolymerization of ethylene with polar vinyl monomers, a highly challenging reaction. ${ }^{5-7}$

Ar-BIANs applied as ancillary ligands in catalysts for polymerization reactions share some common features: $i$. the two nitrogen atoms bear identical aryl rings; ii. these aryl rings are almost invariably substituted in the ortho and/or para positions; iii. the nature and the number of substituents affect the yield, the selectivity, ${ }^{4} 8$ and the microstructure of the polymer, ${ }^{8}$ and the relative amount of comonomers inserted into the polymer chain in both $\alpha$-olefins ${ }^{9}$ and in ethylene/polar vinyl monomer copolymerization. ${ }^{6,10,11}$

Palladium complexes with ortho substituted Ar-BIANs ( ${ }^{\circ}$ Ar-BIAN) were applied as model compounds to unravel the mechanism of the polymer chain growth during the $\mathrm{CO} /$ alkene copolymerization. ${ }^{12}$ Some of these complexes were also tested as precatalysts in the CO/4-Mestyrene copolymerization (4-Me-styrene $=4$-methylstyrene): low productivity $(15 \mathrm{~g} \mathrm{CP} / \mathrm{g} \mathrm{Pd} ; \mathrm{g}$ $\mathrm{CP} / \mathrm{g} \mathrm{Pd}=$ grams of copolymer per gram of palladium) or inactivity were observed depending on the substituents on the ortho positions. Nevertheless, polyketones made of isotactic stereoblocks of opposite relative configuration were obtained despite the $C_{2 \mathrm{v}}$ symmetry of the ligands. ${ }^{13-15}$ 
For the first time we introduced nonsymmetrical Ar,Ar'-BIANs featured by different aryl rings substituted in meta position on the two N-donors. ${ }^{16}$ The organometallic palladium complexes, $\left[\mathrm{Pd}\left(\mathrm{CH}_{3}\right)\left(\mathrm{CH}_{3} \mathrm{CN}\right)\left({ }^{m} \mathrm{Ar}-\mathrm{BIAN}\right)\right]\left[\mathrm{PF}_{6}\right]$, with symmetrically and nonsymmetrically meta substituted Ar-BIANs ( $\left.{ }^{m} \mathrm{Ar}-\mathrm{BIAN}\right)$, were applied as catalysts in $\mathrm{CO} /$ vinyl arene copolymerization. We found that moving the substituents on the aryl rings of Ar-BIAN from the ortho to the meta positions resulted in an enhancement of productivity of more than two orders of magnitude, and a productivity value of $3.70 \mathrm{~kg} \mathrm{CP} / \mathrm{g}$ Pd was reached. ${ }^{17}$ Polyketones with an atactic microstructure and $\mathrm{Mw}$ of $47000(\mathrm{Mw} / \mathrm{Mn}=2.0)$ were produced. Both productivity and molecular weight were affected by the nature and the number of substituents on the ${ }^{m}$ Ar-BIANs. The catalysts with the nonsymmetrical Ar,Ar'-BIAN are more productive than those having the corresponding symmetrical ligands and lead to polyketones of higher molecular weight.

The positive effect of nonsymmetrical Ar,Ar'-BIAN ligands has been very recently demonstrated even in the ethylene/methyl acrylate cooligomerization: the catalyst with the nonsymmetrical ligand showed a higher productivity and a higher content of the inserted polar monomer with respect to those with the related symmetrical ligands. ${ }^{18}$

These catalytic results suggest that the subtle unbalance of the electronic and steric properties of the $\mathrm{N}$-donor atoms of the Ar-BIAN ligands has a positive effect on the catalyst performance and, thanks to the similarity between these two copolymerization reactions, it might indicate the validity of a more general principle.

With the aim to unravel the nature of the different catalytic behavior of complexes with symmetrical and nonsymmetrical Ar-BIANs we have chosen the CO/vinyl arene copolymerization as model reaction and on palladium complexes with selected ligands (Figure 1) we have performed: 1. kinetic investigations; 2. the related modelization; 3. in situ NMR mechanistic studies on the reactivity of the complexes with the comonomers. In addition, with these purposes the series of nonsymmetrical ligands has been extended to a new component, ligand $\mathbf{3}$, featured by one aryl ring substituted in meta and para positions with methoxy groups and the other aryl ring having fluorine atoms in the meta positions. 

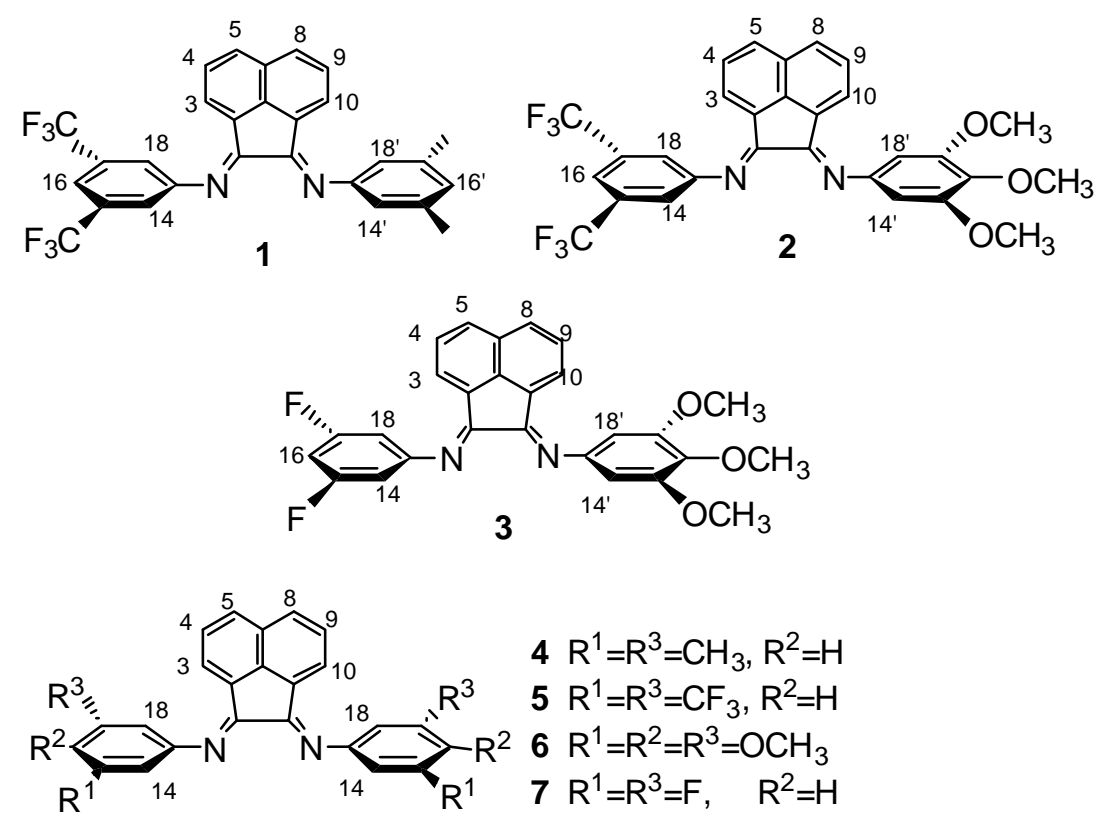

Figure 1. The studied Ar-BIANs and their numbering scheme.

\section{Results and Discussion}

\section{Synthesis and characterization of the new ligands and the related Pd-complexes}

Ligands 3 and 7 are reported here for the first time. The synthetic methodology for ligand 7 is based on the well known condensation reaction of acenaphthenequinone with 3,5-difluoro aniline in the presence of $\mathrm{ZnCl}_{2}$ as templating agent. ${ }^{19,20}$

The synthesis of the new nonsymmetrical Ar,Ar'-BIAN 3 was performed by the transimination reaction between the zinc derivative of ligand 7 and 3,4,5-trimethoxy aniline (Scheme 1), similarly to what was previously described by some of us for other nonsymmetrical Ar,Ar'-BIAN derivatives. ${ }^{16}$ The reaction proceeds quickly and the mixed ligand could be isolated in $52 \%$ yield after chromatographic purification. It should be noted that previously mixed ligands had only been obtained by this methodology when the starting compound had two trifluoromethyl groups on each aryl ring, according to the idea that electron-withdrawing substituents on the starting Ar-BIAN should render transimination easier. The present result indicates that even less electron-withdrawing groups can be efficiently used in this protocol. 
<smiles>O=C1C(=O)c2cccc3cccc1c23</smiles>
$+2$

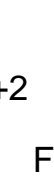<smiles>Nc1cc(F)cc(F)c1</smiles><smiles>CC(C)COCCOC(C)(C)C</smiles>
$+\mathrm{ZnCl}_{2}$<smiles>COc1cc(N)cc(OC)c1OC</smiles>

$\mathrm{MeOH}, \mathrm{RT}$

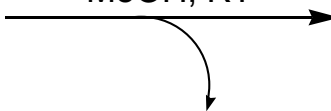<smiles>Nc1cc(F)cc(F)c1</smiles>

$\mathrm{K}_{2} \mathrm{C}_{2} \mathrm{O}_{4}, \mathrm{H}_{2} \mathrm{O} / \mathrm{CH}_{2} \mathrm{Cl}_{2}$

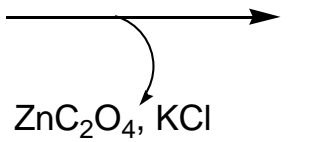<smiles></smiles><smiles>COc1cc(/N=C2/C(=Nc3cc(F)cc(F)c3)c3cccc4cccc2c34)cc(OC)c1OC</smiles>

Scheme 1. Synthetic pathway for ligand 3.

The monocationic $\mathrm{Pd}$ complexes, $\left[\mathrm{Pd}\left(\mathrm{CH}_{3}\right)\left(\mathrm{CH}_{3} \mathrm{CN}\right)(\mathrm{Ar}-\mathrm{BIAN})\right]\left[\mathrm{PF}_{6}\right] \quad \mathbf{1 b}-\mathbf{7 b}$, applied as precatalysts in the model reaction were synthesized by halogen abstraction on the corresponding neutral derivatives, $\left[\mathrm{Pd}\left(\mathrm{CH}_{3}\right) \mathrm{Cl}(\mathrm{Ar}-\mathrm{BIAN})\right]\left[\mathrm{PF}_{6}\right]$ 1a-7a, following the literature methodology (Scheme 2). ${ }^{17,21}$ 


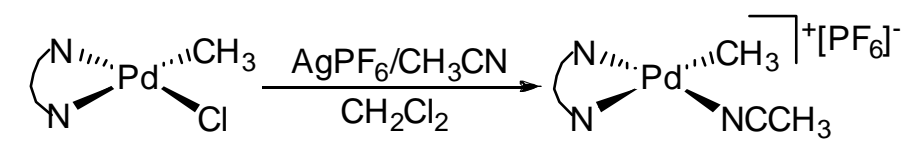
1a: N-N $=1$
2a: $\mathrm{N}-\mathrm{N}=\mathbf{2}$
3a: $\mathrm{N}-\mathrm{N}=3$
4a: $\mathrm{N}-\mathrm{N}=4$
5a: $\mathrm{N}-\mathrm{N}=\mathbf{5}$
6a: $\mathrm{N}-\mathrm{N}=\mathbf{6}$
7a: $N-N=7$
1b: $\mathrm{N}-\mathrm{N}=1$
2b: $\mathrm{N}-\mathrm{N}=\mathbf{2}$
3b: $\mathrm{N}-\mathrm{N}=3$
4b: $\mathrm{N}-\mathrm{N}=4$
5b: $\mathrm{N}-\mathrm{N}=5$
6b: $\mathrm{N}-\mathrm{N}=6$
7b: $\mathrm{N}-\mathrm{N}=7$

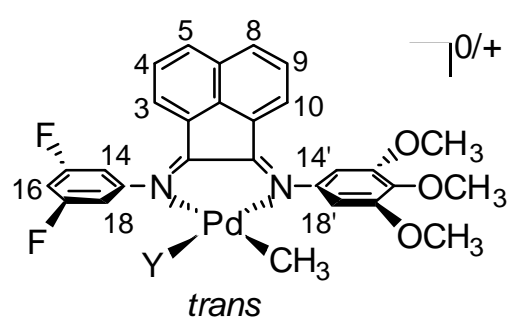

$\mathrm{Y}=\mathrm{Cl}, \mathrm{CH}_{3} \mathrm{CN}$

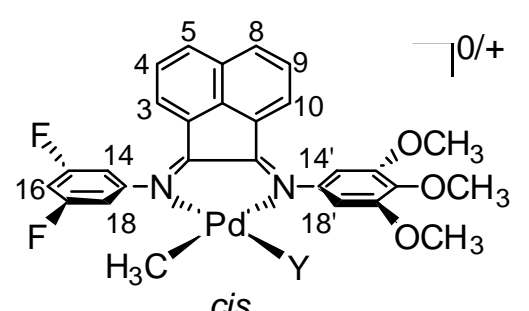

$\mathrm{Y}=\mathrm{Cl}, \mathrm{CH}_{3} \mathrm{CN}$

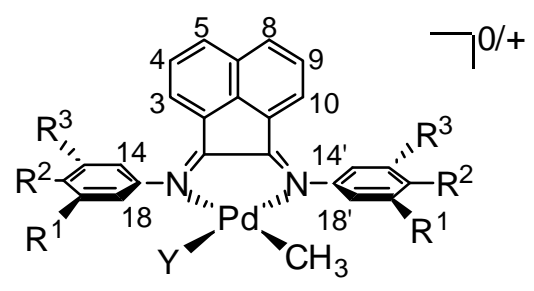

$\mathrm{Y}=\mathrm{Cl}, \mathrm{CH}_{3} \mathrm{CN}$

Scheme 2. Synthetic pathway for the monocationic complexes $\mathbf{1 b}-\mathbf{7 b}$ and the numbering scheme for both neutral and monocationic derivatives.

Ligands 3 and 7 and the related palladium complexes were characterized in solution by NMR spectroscopy. For Ar-BIANs, $(E, E)$ and $(E, Z)$ isomers are possible regarding to the relative configuration of the aryl rings with respect to the $\mathrm{C}=\mathrm{N}$ imine bonds. In general, only the $E, E$ isomer is observed for symmetrical Ar-BIANs, ${ }^{19}$ but a variable amount of the $E, Z$ isomer is always found in the case of nonsymmetrical Ar,Ar'-BIAN derivatives ${ }^{16-18,20}$ and for alkyl-BIANs. ${ }^{22,23}$ For both ligands 3 and 7 , the ${ }^{1} \mathrm{H}$ NMR spectrum recorded at room temperature in $\mathrm{CDCl}_{3}$ and $\mathrm{CD}_{2} \mathrm{Cl}_{2}$, respectively, indicated the presence in solution of the $E, E$ isomer only. Though this was expected for the latter, it is surprising for the former. The NMR characterization of complexes $\mathbf{7 a}$ and $\mathbf{7 b}$ was in line with data reported in the literature for analogous compounds with symmetrically substituted Ar-BIANs. ${ }^{12,17,18}$ In the case of complexes $\mathbf{3 a}$ and $\mathbf{3 b}$, bearing the nonsymmetrical ligand $\mathbf{3}$ on palladium, in analogy with what we reported for complexes $\mathbf{1 a}, \mathbf{2 a}$ and $\mathbf{1 b}, \mathbf{2 b},{ }^{17}$ cis and trans isomers were observed in solution differing in the relative position of the $\mathrm{Pd}-\mathrm{CH}_{3}$ fragment with respect to the two halves of the ligand. We define as trans the isomer having the $\mathrm{Pd}-\mathrm{CH}_{3}$ fragment, or more generally the $\mathrm{Pd}-\mathrm{C}$ bond, trans to the $\mathrm{Pd}-\mathrm{N}$ bond of the aryl ring substituted with electron- 
withdrawing groups (Scheme 2). According to the ${ }^{1} \mathrm{H}$ NMR spectra the trans to cis ratio was 3:1 and 5:1 for $\mathbf{3} \mathbf{a}$ and $\mathbf{3 b}$, respectively.

Single crystals suitable for X-ray analysis were obtained for complexes 1a and 3a by slow diffusion of diethyl ether into a $\mathrm{CD}_{2} \mathrm{Cl}_{2}$ solution of the complexes kept at $4{ }^{\circ} \mathrm{C}$ for one week. The crystal structure of complex $\left[\mathrm{Pd}\left(\mathrm{CH}_{3}\right) \mathrm{Cl}(\mathbf{5})\right]$ with the symmetrically substituted ${ }^{m} \mathrm{Ar}-\mathrm{BIAN}$ with $\mathrm{CF}_{3}$ groups in meta position, has already been reported, ${ }^{24}$ thus allowing a comparison of its structural features with those of $\mathbf{1 a}$ and $\mathbf{3 a}$.

In the crystals of complexes with the nonsymmetrical Ar,Ar'-BIANs $\mathbf{1}$ and $\mathbf{3}$, only the trans isomer was detected in the unit cell (Figure 2, Table 1), in agreement with the NMR characterization in solution that showed this species as the prevailing isomer. This confirms our previous report regarding complex $\left[\mathrm{Pd}\left(\mathrm{CH}_{3}\right) \mathrm{Cl}(\mathbf{8})\right]$, where $\mathbf{8}$ is the nonsymmetrical $\mathrm{Ar}$,Ar'-BIAN featured by one aryl ring substituted by $\mathrm{CH}_{3}$ groups in ortho position and the other ring having $\mathrm{CF}_{3}$ substituents in meta. $^{18}$

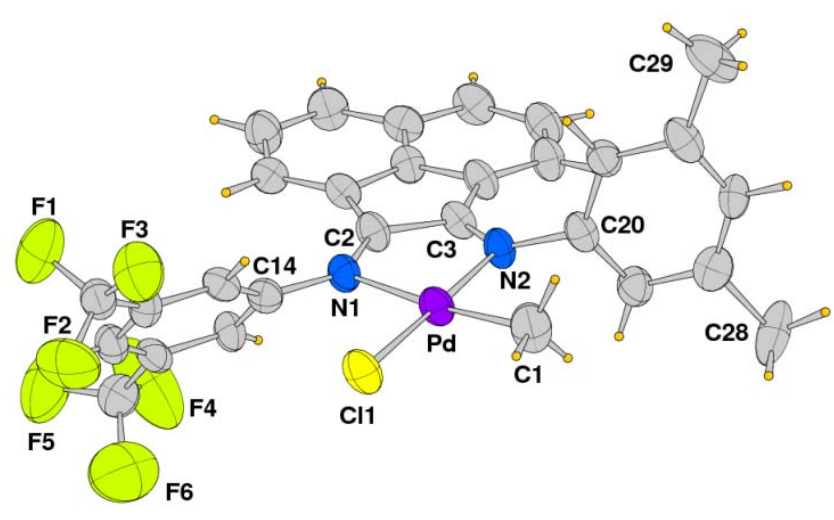

$1 \mathbf{a}$

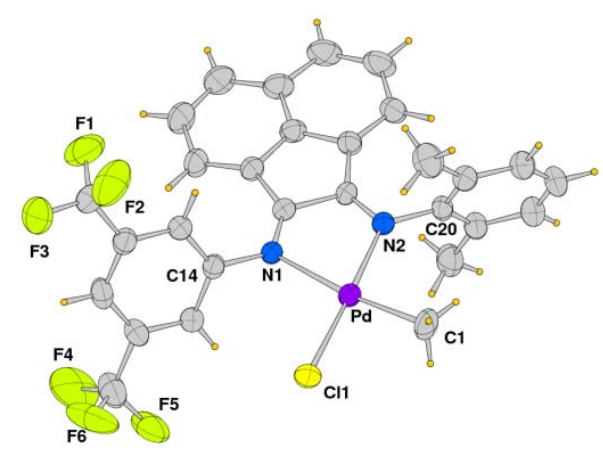

$8 \mathbf{a}$

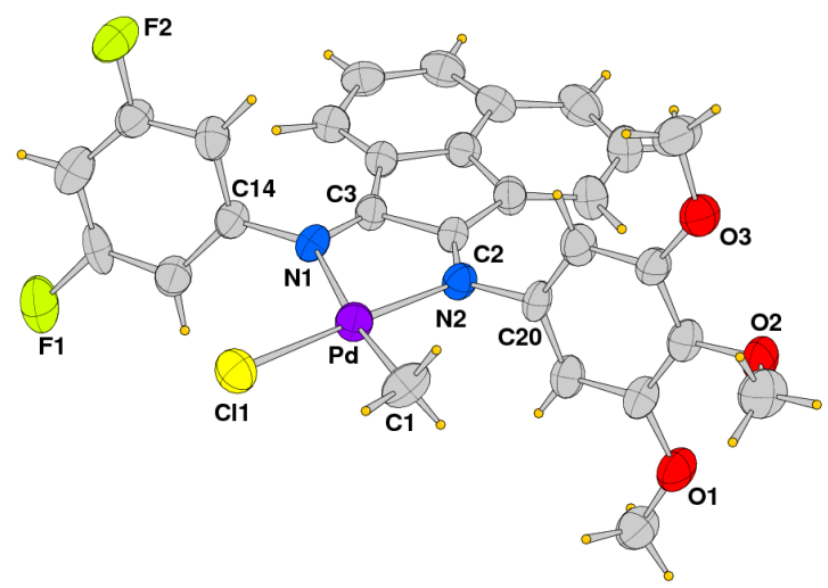

3a

Figure 2. The ORTEP drawing (thermal ellipsoids at $35 \%$ probability level) of complexes 1a, 3a and $\mathbf{8} \mathbf{a}^{18}$. 
Table 1. Selected bond lengths and angles for complexes 1a and 3a.

\begin{tabular}{|l|c|c|}
\hline \multicolumn{2}{|c|}{ 1a } & 3a \\
\hline Lengths $(\AA)$ & $2.225(8)$ & $2.205(5)$ \\
\hline Pd-N(1) & $2.063(7)$ & $2.042(5)$ \\
\hline Pd-N(2) & $2.011(10)$ & $2.020(6)$ \\
\hline Pd-C(1) & $2.294(3)$ & $2.279(2)$ \\
\hline Pd-Cl(1) & & \\
\hline Angles $\left(^{\circ}\right)$ & $78.3(3)$ & $78.7(2)$ \\
\hline $\mathrm{N}(1)-\mathrm{Pd}-\mathrm{N}(2)$ & $171.6(3)$ & $172.1(3)$ \\
\hline $\mathrm{N}(1)-\mathrm{Pd}-\mathrm{C}(1)$ & $99.2(2)$ & $100.56(15)$ \\
\hline $\mathrm{N}(1)-\mathrm{Pd}-\mathrm{Cl}(1)$ & $93.3(4)$ & $93.9(3)$ \\
\hline $\mathrm{N}(2)-\mathrm{Pd}-\mathrm{C}(1)$ & $177.3(2)$ & $177.17(17)$ \\
\hline $\mathrm{N}(2)-\mathrm{Pd}-\mathrm{Cl}(1)$ & $89.2(3)$ & $87.0(2)$ \\
\hline $\mathrm{C}(1)-\mathrm{Pd}-\mathrm{Cl}(1)$ & & \\
\hline
\end{tabular}

In the complexes the palladium ion attains the expected square planar coordination geometry. In agreement with the trans influence of the $\mathrm{Pd}-\mathrm{CH}_{3}$ fragment, in both complexes the $\mathrm{Pd}-\mathrm{N} 1$ bond distance trans to it is remarkably longer than the other Pd-N bond length. If a comparison on coordination bond distances is limited to complexes 1a, 3a and 5a (all having ${ }^{m} \mathrm{Ar}-\mathrm{BIAN}$ ), the Pd$\mathrm{N} 1$ bond length is $2.225(8), 2.205(5)$ and 2.227(4) $\AA$, respectively. This indicates that ligand 3 appears to be stronger bonded to palladium, as a result of lower steric hindrance and electronwithdrawing effect of $\mathrm{F}$ with respect to $\mathrm{CF}_{3}$. This is also supported by the corresponding values measured for the Pd-N2 bond distance, trans to chloride, that is the shortest among the three (2.042(5) $\AA$ for 3a vs 2.063(7) and 2.073(5) $\AA$ for 1a and 5a, respectively).

Another similarity in the structural features of the studied complexes is concerned with the orientation of the substituted phenyl rings with respect to the BIAN plane. The dihedral angle between the BIAN plane and the aryl ring on the side of the $\mathrm{Pd}-\mathrm{Cl}$ bond falls in the range 52.5 $64.5^{\circ}$, while that on the side of the $\mathrm{Pd}-\mathrm{CH}_{3}$ bond is $76.4-80.06^{\circ}$ indicating the aryl ring almost orthogonally oriented with respect to the BIAN plane. These values indicate a greater conformational freedom on the $\mathrm{Pd}-\mathrm{Cl}$ side than on the $\mathrm{Pd}-\mathrm{CH}_{3}$ part reasonably due to the less steric hindrance of chloride with respect to that of the methyl group.

For the complexes with the nonsymmetrical Ar,Ar'-BIANs, the preference, both in solution and in solid state, towards the trans isomer is in agreement with the literature data on palladium complexes 
with bidentate nitrogen-donor ligands having electronically nonequivalent $\mathrm{N}$ atoms. ${ }^{21,25-28}$ and with the general trend that the weakest ligand (here the nitrogen atom bearing the fluorine substituted aryl ring) is found trans to the stronger trans-labilizing ligand (here the methyl group). The opposite preference towards the cis isomer was observed in case of high steric hindrance around the palladium centre. $^{29}$

\section{Kinetic investigations and modeling}

\section{General outcome}

We reported that the monocationic complexes $\mathbf{1 b}, \mathbf{2 b}, \mathbf{4 b}-\mathbf{6 b}$ generated active catalysts for the $\mathrm{CO} /$ styrene and the $\mathrm{CO} / 4-\mathrm{Me}$-styrene copolymerization yielding the corresponding polyketones with an atactic microstructure. ${ }^{17}$ Both productivity and molecular weight of the synthesized copolymers were affected by the nature of the substituents. Even though some differences in the order of productivity of the catalysts were observed for the two alkenes and the effect of the ligand nature was more pronounced in case of styrene than for 4-methylstyrene, for both alkenes the catalysts with the nonsymmetrical Ar,Ar'-BIANs $\mathbf{1}$ and $\mathbf{2}$ were found the most productive within the series. ${ }^{17}$ In particular, with styrene, ligand 2 generated the most productive catalyst among those tested $(3.70 \mathrm{~kg} \mathrm{CP} / \mathrm{g} \mathrm{Pd})$, while in the case of 4-Me-styrene the highest productivity was reached with the catalyst obtained from complex $1 \mathbf{b}(2.36 \mathrm{~kg} \mathrm{CP} / \mathrm{g} \mathrm{Pd})$. For both alkenes, the catalyst with ligand 1 showed a productivity remarkably higher than that of the catalysts with the related symmetrically substituted ${ }^{m} \mathrm{Ar}-\mathrm{BIANs}, \mathbf{4}$ and 5. The same trend was observed for the $\mathrm{CO} / \mathrm{styrene}$ copolymerization catalyzed by $\mathbf{2 b}$ with respect to $\mathbf{5 b}$ and $\mathbf{6 b}$, while in the $\mathrm{CO} / 4-\mathrm{Me}$-styrene copolymerization the productivity obtained with $\mathbf{2 b}$ was slightly lower than that obtained with $\mathbf{6 b}$ $(1.64 \mathrm{~kg} \mathrm{CP} / \mathrm{g} \mathrm{Pd}$ vs $1.95 \mathrm{~kg} \mathrm{CP} / \mathrm{g} \mathrm{Pd}) .{ }^{17}$ Moreover, in the $\mathrm{CO} /$ styrene copolymerization no formation of inactive palladium metal was observed, whereas in the case of $\mathrm{CO} / 4-\mathrm{Me}$-styrene copolymerization catalyst decomposition was sometimes observed even in the presence of 1,4benzoquinone. $^{17}$

To have a better understanding of the catalytic behavior of these complexes some kinetic investigations were performed by taking advantage of an automated parallel reactor (AMTEC SPR16), allowing to monitor the CO uptake during the copolymerization reactions. All the catalytic tests were carried out in 2,2,2-trifluoroethanol (TFE) in the presence of 1,4-benzoquinone (BQ; $[\mathrm{BQ}] /[\mathrm{Pd}]=5$ ), at $\mathrm{T}=30{ }^{\circ} \mathrm{C}$, under a preferential $\mathrm{CO}$ pressure of 5 bar, and with a ratio $[$ alkene $] /[\mathrm{Pd}]=22000$ for the runs involving 4-methylstyrene and 25000 for those with styrene. The large excess of the vinyl arene used ensures to be in conditions of pseudo-zero order with respect to the alkene even for longer reaction time. 
As a general comment, depending on the nature of the ligand bonded to palladium, within the first 24 hours of reaction some catalysts show an almost linear dependence of CO uptake with time while others deactivate to a much higher extent. This catalytic behavior is different from that found by us for analogous palladium complexes with ligands belonging to the family of 1,10 phenanthroline ${ }^{21}$ that over a range of $90 \mathrm{~h}$ showed a linear dependence of CO uptake with time, in agreement with the stronger coordinating capability of phenanthroline ligands with respect to that of Ar-BIANs. $^{20}$

The comparison of the CO uptake curves of precatalyst $\mathbf{1 b}$ with those of complexes $\mathbf{4 b}$ and $\mathbf{5 b}$ having the corresponding symmetrical ${ }^{m}$ Ar-BIANs probes evidence that for both alkenes the catalyst with ligand $\mathbf{5}$ is deactivated within the first hour of reaction, while for the catalyst with ligand $\mathbf{1}$ deactivation is limited and the complex with $\mathbf{4}$ is the only one that does not show any deactivation process for at least 24 hours (Figure 3). With 4-Me-styrene, the active species containing the nonsymmetrical ligand $\mathbf{1}$ is remarkably more productive than the catalysts with the two symmetrical counterparts (Figure 3, left), while for styrene the same trend is observed in the first 14 hours of reaction. Afterwards the activity of the catalyst with ligand $\mathbf{1}$ decreases and becomes lower than that of the catalyst with ligand 4 (Figure 3, right).

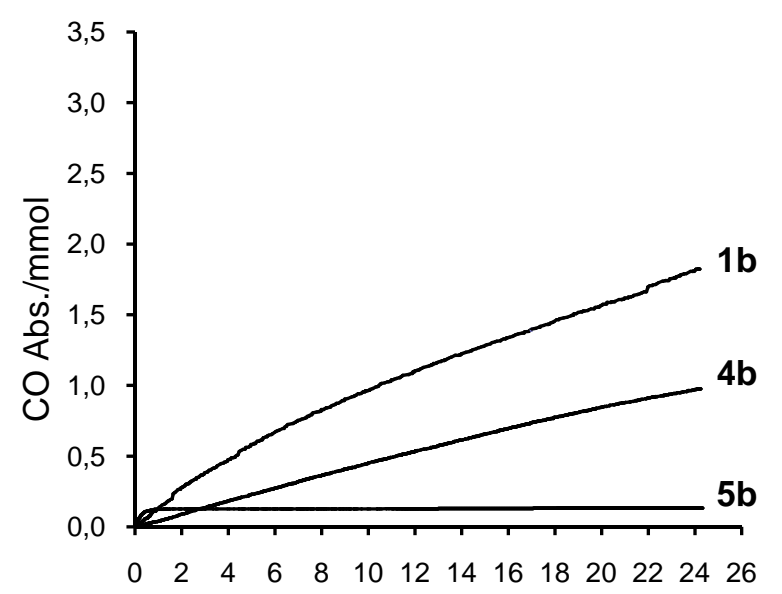

$\mathrm{t} / \mathrm{h}$

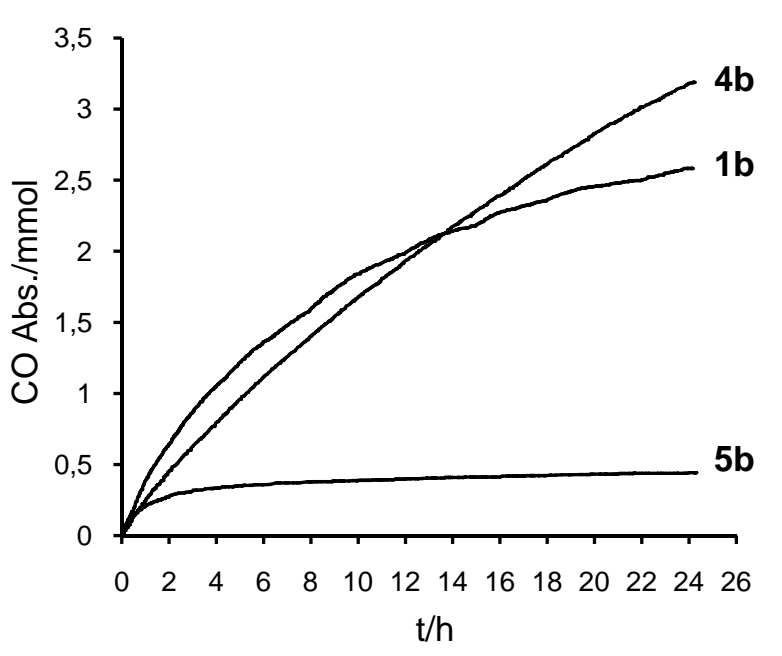

$5 b$

Figure 3. $\mathrm{CO}$ /vinyl arene copolymerization: effect of Ar-BIAN ligand on CO uptake. Catalyst precursor: $\left[\mathrm{Pd}\left(\mathrm{CH}_{3}\right)\left(\mathrm{CH}_{3} \mathrm{CN}\right)(\mathrm{Ar}-\mathrm{BIAN})\right]\left[\mathrm{PF}_{6}\right](\mathbf{1 b}, \mathbf{4 b}, \mathbf{5 b})$. Reaction conditions: $n_{\mathrm{Pd}}=0.106 \times 10^{-5}$ mol, $T=30{ }^{\circ} \mathrm{C}$, TFE $V=5 \mathrm{~mL}, P_{\mathrm{CO}}=5 \mathrm{bar}, t=24 \mathrm{~h},[\mathrm{BQ}] /[\mathrm{Pd}]=5$, vinyl arene $V=3 \mathrm{~mL}$, $[$ styrene $] /[\mathrm{Pd}]=25000,[4-\mathrm{Me}-$ styrene $] /[\mathrm{Pd}]=22000$. Left: CO/4-Me-styrene; Right: CO/styrene copolymerization. 
When the same comparison is performed among the catalysts with the nonsymmetrical ligand $\mathbf{2}$ and those with the related symmetrical ligands $\mathbf{5}$ and $\mathbf{6}$, the active species containing ligand $\mathbf{6}$ was found much more productive than that having the related nonsymmetrical Ar,Ar'-BIAN 2 in the CO/4-Mestyrene copolymerization (Figure 4, left).
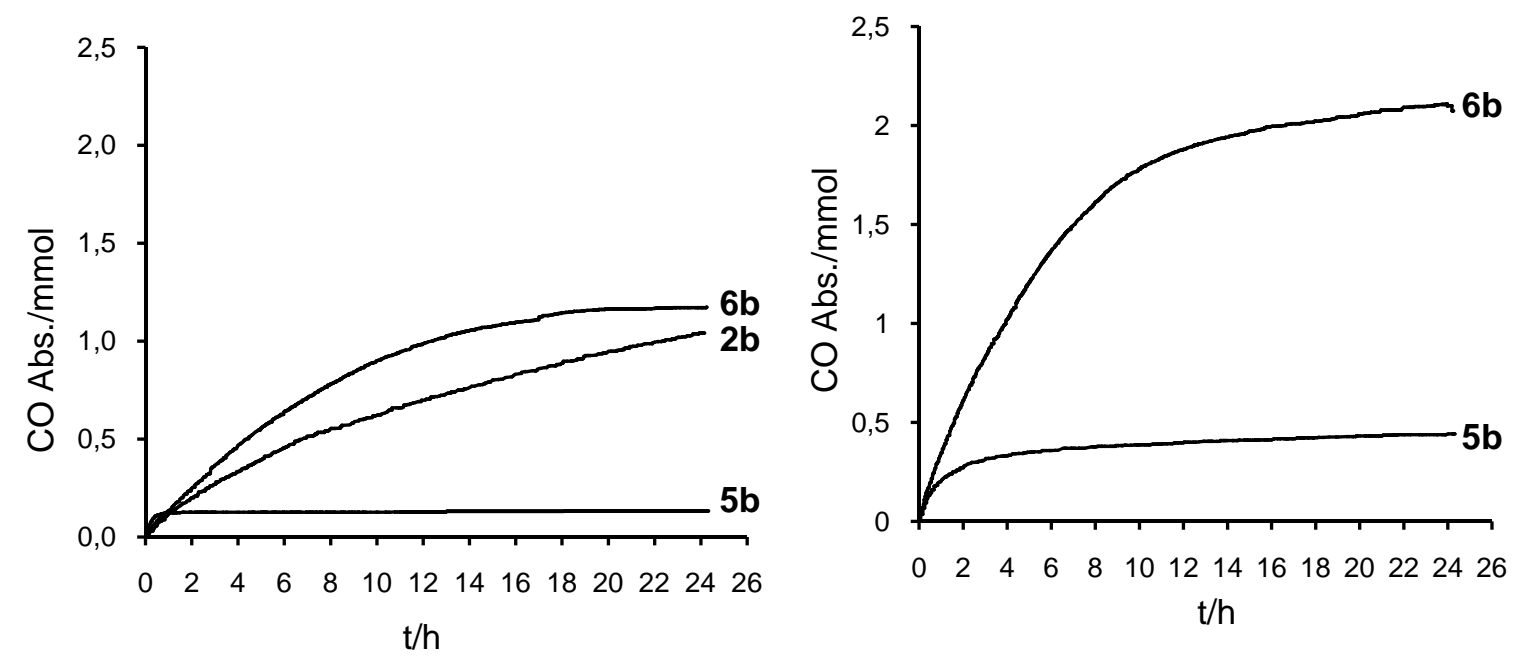

Figure 4. CO/vinyl arene copolymerization: effect of Ar-BIAN ligand on CO uptake. Catalyst precursor: $\left[\mathrm{Pd}\left(\mathrm{CH}_{3}\right)\left(\mathrm{CH}_{3} \mathrm{CN}\right)(\mathrm{Ar}-\mathrm{BIAN})\right]\left[\mathrm{PF}_{6}\right](\mathbf{2 b}, \mathbf{5 b}, \mathbf{6 b})$. Reaction conditions: see Figure 3. Left: CO/4-Me-styrene; Right: CO/styrene.

The lower productivity of $\mathbf{2 b}$ with respect to that of $\mathbf{6 b}$ might be related to the presence of the $\mathrm{CF}_{3}$ groups on one of the aryl rings of 2 that might have a negative effect for steric reasons. This hypothesis is supported by the investigation of the catalytic behavior of complex $\mathbf{3 b}$, where the nonsymmetrical Ar,Ar'-BIAN 3 is analogous to 2 but with fluorine substituents in place of $\mathrm{CF}_{3}$ groups (Figure 5). 

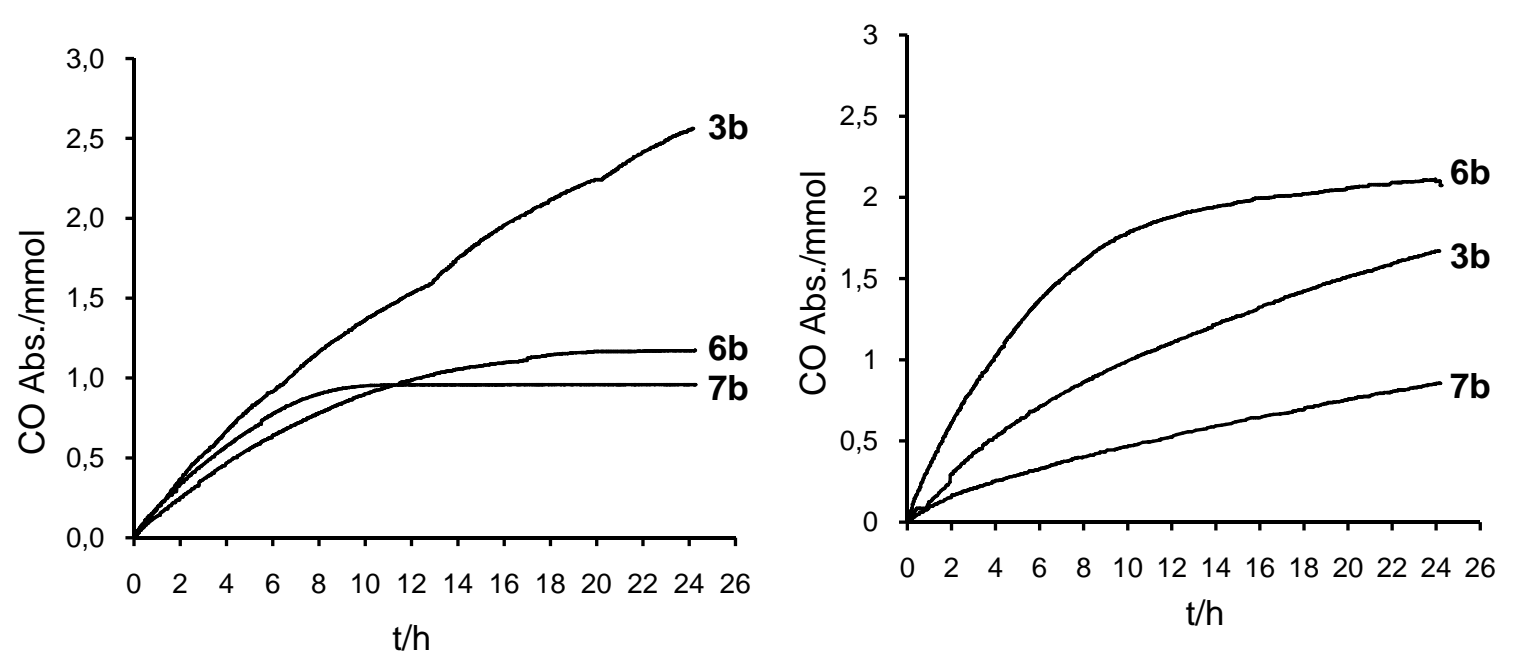

Figure 5. CO/vinyl arene copolymerization: effect of Ar-BIAN ligand on CO uptake. Catalyst precursor: $\left[\mathrm{Pd}\left(\mathrm{CH}_{3}\right)\left(\mathrm{CH}_{3} \mathrm{CN}\right)(\mathrm{Ar}-\mathrm{BIAN})\right]\left[\mathrm{PF}_{6}\right](\mathbf{3 b}, \mathbf{6 b}, \mathbf{7 b})$. Reaction conditions: see Figure 3. Left: $\mathrm{CO} / 4-\mathrm{Me}-$ styrene; right: $\mathrm{CO} /$ styrene.

By comparing the $\mathrm{CO}$ uptake curves of $\mathbf{3 b}, \mathbf{6 b}$ and $\mathbf{7 b}$ it is evident that, in analogy with the trends involving 5b, the symmetrical ligand with the electron-withdrawing substituent fluorine, 7, generates the least productive species for both alkenes. The catalyst with the nonsymmetrical ligand $\mathbf{3}$ is found to be less productive than that with the corresponding symmetrical methoxy-substituted Ar-BIAN 6 for the CO/styrene copolymerization (Figure 5, right), whereas in the CO/4-Me-styrene copolymerization catalyst with $\mathbf{3}$ shows a remarkably higher productivity than the active species with the symmetrically substituted ligand 6 (Figure 5, left). Thus, at least for the 4-Me-styrene the replacement of the $\mathrm{CF}_{3}$ groups with fluorine atoms had a remarkable positive effect, in agreement with the lower value of both the Hammett $\sigma$ constant (electronic effect) and the Taft parameter (steric effect) of fluorine with respect to $\mathrm{CF}_{3}{ }^{30}$

\section{Set up of the kinetic modeling}

Although the aforementioned differences in total productivity are well defined, a closer examination of the reaction profiles evidences that the reason for these behaviors is far from clear cut. In most cases productivity inversions are noted over time with different catalysts and some of those showing the lowest final productivity are indeed the most active in the early stages of the reaction, suggesting that catalyst deactivation plays a relevant role in the final productivity order.

In order to gain a better understanding of the kinetic outcome of the different reactions and of the productivity inversions mentioned above, we engaged in a mathematical modeling of the reaction profiles that could take into account both the chain propagation and the catalyst deactivation. The 
followed approach is not a standard one and several problems needed to be solved. In order to keep the article text as compact as possible, only a general description of the method employed is reported, whereas more details can be found in the Supplementary Information.

A general reaction pathway evidencing the catalyst decomposition is shown in Scheme 3. A palladium(II) species catalyzes the copolymerization reaction with a kinetic constant $\mathrm{k}_{\mathrm{p}}$ (the kinetic order with respect to the reagents has been left unspecified for the moment). Since the olefin is present in large excess and CO is continuously replenished, the concentration of both reagents is constant during the reaction and the rate depends only on the active palladium concentration, which decreases with time because of catalyst decomposition:

rate $=\mathrm{k}_{1}\left[\mathrm{Pd}^{\mathrm{II}}\right]$

where $\mathrm{k}_{1}$ is the apparent first order kinetic constant with respect to the active catalyst concentration.

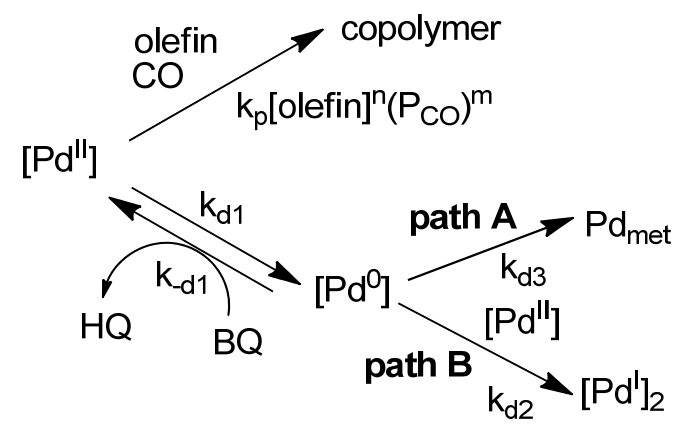

Scheme 3. Simplified reaction pathways for kinetic modeling.

Experimentally, the actual reaction rate is measured by the CO consumption $(\mathrm{mmol} / \mathrm{h})$, but in order to have the kinetic constants expressed in the usual (time) $)^{-1}$ units (for first order kinetics) it is better to divide the $\mathrm{CO}$ absorption (in $\mathrm{mmol}$ ) by the reaction solution volume ( $\mathrm{V}=8 \mathrm{~mL}$ for all reactions). That is:

rate $=\mathrm{d}[(\mathrm{CO}$ abs $/ \mathrm{mmol}) /(\mathrm{V} / \mathrm{mL})] / \mathrm{dt}=\mathrm{k}_{\mathrm{p}}\left[\mathrm{Pd}^{\mathrm{II}}\right][\text { olefin }]^{\mathrm{n}}\left(\mathrm{P}_{\mathrm{CO}}\right)^{\mathrm{m}} \quad=\mathrm{k}_{1}\left[\mathrm{Pd}^{\mathrm{II}}\right]$

where $\left[\mathrm{Pd}^{\mathrm{II}}\right]$ depends on time.

As far as catalyst decomposition is concerned, it is well recognized that in the present catalytic system this is due to palladium(II) reduction, as supported by the fact that benzoquinone retards such deactivation by oxidizing back the palladium(0) complex (processes associated to $\mathrm{k}_{\mathrm{d} 1}$ and $\mathrm{k}_{-\mathrm{d} 1}$ in Scheme 3) and that metallic palladium is observed sometimes after complete catalyst deactivation. There is little doubt that the initial step for decomposition is the reduction of a single 
palladium(II) complex to palladium(0). Although several possibilities exist for such a process, it is almost surely described by a first order kinetic with respect to palladium(II). What occurs later is less obvious. Several papers have been devoted to the kinetics of metallic nanoparticles formation, but they usually focus on later stages of the reaction. ${ }^{31,32}$ As far as the early stages of decomposition are concerned, we can identify two general reaction pathways.

In the first pathway (path A in Scheme 3), the palladium(0) complex decomposes by an irreversible unimolecular pathway, e.g. an irreversible loss of the nitrogen ligand, eventually giving metallic palladium. Alternatively, the palladium(0) complex can react with a palladium(II) complex to afford an inactive palladium(I) dimer (path B in Scheme 3). Precedents exist for such a process. ${ }^{33-35}$ Very recently some of us identified a series of complexes of general structure $\left[\operatorname{Pd}^{\mathrm{I}} \mathrm{L}^{2} \mathrm{X}(\mu-\mathrm{CO})\right]_{2}\left(\mathrm{~L}^{2}=\right.$ 1,10-phenanthroline, 2,2'-bipyridine or their substituted analogues, $\mathrm{X}=$ halide, carboxylate, $-\mathrm{C}(\mathrm{O}) \mathrm{OMe})$ as intermediates in the reduction of palladium(II) complexes by $\mathrm{CO}$ and water or alcohols under conditions close to those employed in the presently studied system ${ }^{36}$ and the formation of the corresponding Ar-BIAN complexes may as well occur easily. ${ }^{37}$

Modeling the complete system without knowing the benzoquinone concentration vs. time profile is not possible in general, even if the steady state approximation is applied to the $\operatorname{Pd}(0)$ complex. However, in those cases in which deactivation is limited, it can be approximated that benzoquinone concentration is essentially constant during the reaction. Under these conditions paths $\mathrm{a}$ and $\mathrm{b}$ can be respectively approximately described by a first and a second kinetics with respect to palladium(II) concentration (Scheme 4). Note that the exact identity of the inactive species formed during the decomposition is not known and differs between the two pathways. However, this is not relevant at all to the kinetic of the copolymerization reaction as experimentally measured.

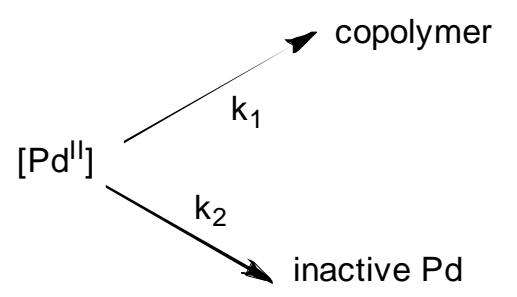

Path a: First order decomposition

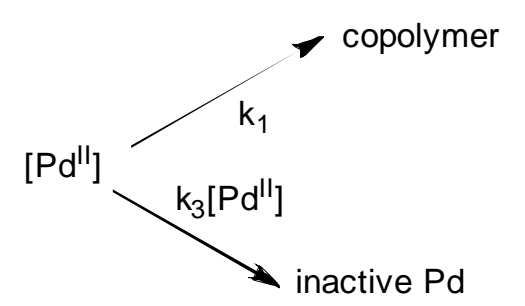

Path b: Second order decomposition

Scheme 4. 
The first order decomposition is described by equations 3 and 4:

$\mathrm{d}\left[\mathrm{Pd}^{\mathrm{II}}\right] / \mathrm{dt}=-\mathrm{k}_{2}\left[\mathrm{Pd}^{\mathrm{II}}\right]$

$\left[\mathrm{Pd}^{\mathrm{II}}\right]_{\mathrm{t}}=\left[\mathrm{Pd}^{\mathrm{II}}\right]_{0} \mathrm{e}^{-\mathrm{k} 2 \mathrm{t}}$

Where $\left[\mathrm{Pd}^{\mathrm{II}}\right]_{0}$ and $\left[\mathrm{Pd}^{\mathrm{II}}\right]_{\mathrm{t}}$ are the palladium(II) concentrations at time zero and $\mathrm{t}$ respectively.

From eqs. 4 and 2, eq. 5 is derived, which leads to eq. 6 after integration.

rate $=\mathrm{d}[(\mathrm{CO} \mathrm{abs}) / \mathrm{V}] / \mathrm{dt}=\mathrm{k}_{1}\left[\mathrm{Pd}^{\mathrm{II}}\right]_{0} \mathrm{e}^{-\mathrm{k} 2 \mathrm{t}}$

$(\mathrm{CO}$ abs $) / \mathrm{V}=\left(\mathrm{k}_{1} / \mathrm{k}_{2}\right)\left[\mathrm{Pd}^{\mathrm{II}}\right]_{0}\left(1-\mathrm{e}^{-\mathrm{k} 2 \mathrm{t}}\right)$

where $\left[\mathrm{Pd}^{\mathrm{II}}\right]_{0}=1.32 \times 10^{-4} \mathrm{M}$.

Equation 6 is of the type $Y=a\left(1-e^{-b X}\right)$, a Stirling type function that can be modeled by a suitably modified fitting function in the program Origin, to give the best $\mathrm{a}$ and $\mathrm{b}$ values, from which $\mathrm{k}_{1}$ and $\mathrm{k}_{2}$ are immediately calculated.

For the second order decomposition pathway, an analogous procedure leads to the equations:

$\mathrm{d}\left[\mathrm{Pd}^{\mathrm{II}}\right] / \mathrm{dt}=-\mathrm{k}_{3}\left[\mathrm{Pd}^{\mathrm{II}}\right]^{2}$

$\left[\mathrm{Pd}^{\mathrm{II}}\right]_{\mathrm{t}}=\left[\mathrm{Pd}^{\mathrm{II}}\right]_{0} /\left(1+\mathrm{k}_{3}\left[\mathrm{Pd}^{\mathrm{II}}\right]_{0} \mathrm{t}\right)$

rate $=\mathrm{d}[(\mathrm{CO} \mathrm{abs}) / \mathrm{V}] / \mathrm{dt}=\mathrm{k}_{1}\left[\mathrm{Pd}^{\mathrm{II}}\right]_{0} /\left(1+\mathrm{k}_{3}\left[\mathrm{Pd}^{\mathrm{II}}\right]_{0} \mathrm{t}\right)$

$(\mathrm{CO} \mathrm{abs}) / \mathrm{V}=\left(\mathrm{k}_{1} / \mathrm{k}_{3}\right) \ln \left(1+\mathrm{k}_{3}\left[\mathrm{Pd}^{\mathrm{II}}\right]_{0} \mathrm{t}\right)$

Equation 10 corresponds to a logarithmic function that can again be modeled in Origin.

Fitting by integration of the 4-Me-styrene experiments run under 5 bar CO

The most extensive series of experiments both with styrene and 4-methylstyrene were run under 5 bar $\mathrm{CO}$ and at $[\mathrm{BQ}] /[\mathrm{Pd}]=5$. Since deactivation was clearly lower with the latter substrate, we will start analyzing the corresponding set of data. The plots of $\mathrm{CO}$ absorption vs. time for selected reactions were reported above in Figures 3-5, while the corresponding plots for the complete set of experiments presently discussed is reported in Supplementary Information (Figure S1). 


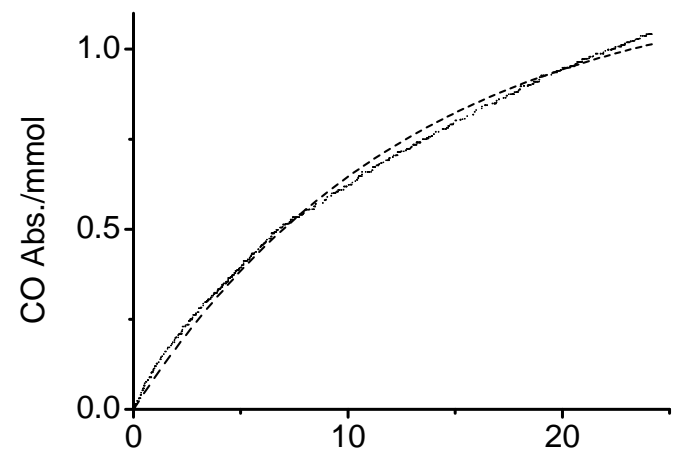

(a) $\mathrm{t} / \mathrm{h}$

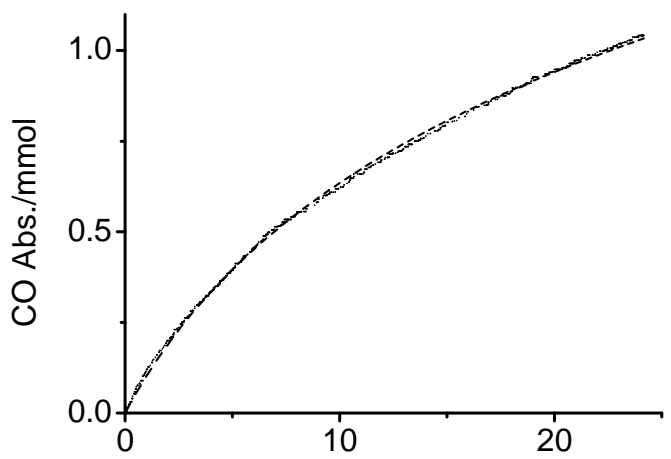

(b) $t / h$

Figure 6. Data for the copolymerization of 4-Me-styrene under 5 bar $\mathrm{CO}([\mathrm{BQ}] /[\mathrm{Pd}]=5)$ and with ligand 2, 3,5-( $\left(\mathrm{CF}_{3}\right)_{2} \mathrm{C}_{6} \mathrm{H}_{3} ; 3,4,5-\left(\mathrm{CH}_{3} \mathrm{O}\right)_{3} \mathrm{C}_{6} \mathrm{H}_{2}$-BIAN. (a) Fitting by eq. 6 (first order decomposition). (b) Fitting by eq. 10 (second order decomposition). Fitting functions are shown as dashed lines (---).

Even from a quick examination of Figure 6 it is clear that eq. 10 fits very well the data in the whole time region, whereas eq. 6 tends to underestimate catalyst decomposition (which is proportional to the second derivative of the $\mathrm{CO}$ absorption plot; see later) at the beginning of the reaction and to overestimate it later. The initial underestimation is especially significant. In fact, if the assumption that benzoquinone concentration is approximately constant was wrong, then catalyst decomposition should be slower than that calculated during the first part of the reaction, when benzoquinone is more abundant. This would result in the model giving an even worse fitting of the data and cannot justify the observed discrepancies. Thus it is clear that the process associated with path a must be discarded as a relevant deactivation mode for palladium, whereas the goodness of the fit obtained by modeling path $\mathrm{b}$ strongly supports its operation. It is worth noting that such a good fit was obtained with only two floating parameters, which would be unlikely to occur if the physical basis of the model were wrong.

Equation 10 could be used to fit the data of five of the reaction profiles with an excellent approximation (adj. $\mathrm{R}^{2}>0.999$ ), but gave significant deviations in the remaining three cases (ligands [3,5- $\left.\left(\mathrm{CF}_{3}\right)_{2} \mathrm{C}_{6} \mathrm{H}_{3}\right]_{2}-\mathrm{BIAN} 5,\left[3,4,5-\left(\mathrm{CH}_{3} \mathrm{O}\right)_{3}-\mathrm{C}_{6} \mathrm{H}_{2}\right]_{2}-\mathrm{BIAN}$ 6,[3,5- $\left.\mathrm{F}_{2} \mathrm{C}_{6} \mathrm{H}_{3}\right]_{2}-\mathrm{BIAN}$ 7), where catalyst decomposition is more evident and the assumption that benzoquinone concentration does not vary is clearly untenable. The values of $\mathrm{k}_{1}$ and $\mathrm{k}_{3}$ best fitting the data for these five cases are reported in Table 2 .

A discussion of the $\mathrm{k}_{1}$ and $\mathrm{k}_{3}$ trends specific for this set of data can be found in the Supplementary Information. However, we have developed a mathematical approach to obtain the desired data even 
for the three reactions that did not give a good fitting with the procedure described above and only the results of the full set of experiments will be described here.

The new approach, described in detail in the Supplementary Information, is based on the following considerations:

1) Since the $\mathrm{CO}$ pressure is kept constant and the olefin concentration is high enough that can be considered constant during the reaction (pseudo zero order kinetics with respect to both $\mathrm{CO}$ and olefin), the reaction rate is proportional only to the active palladium concentration. The reaction rate as a function of time can be obtained by differentiating the $\mathrm{CO}$ absorption curve.

2) Given what said above, the opposite of the derivative of the active catalyst concentration with respect to time, corresponding to the second derivative of the $\mathrm{CO}$ absorption plot, is the rate of decomposition of the catalytic system.

Developing these concepts a series of parallel values for the $\mathrm{k}_{1}$ and $\mathrm{k}_{3}$ values could be determined and are also reported in Table 2 . We named the value calculated by this way $k_{1}{ }^{\prime}$ and $k_{3}{ }^{\prime}$ to distinguish them from those calculated by the fitting procedure described in the previous paragraph, although $\mathrm{k}_{1}$ and $\mathrm{k}_{1}$ ' should ideally be the same. A comparison between the $\mathrm{k}_{1}$ and $\mathrm{k}_{1}{ }^{\prime}$ values in Table 2 for corresponding reactions shows that the agreement is excellent in three out of five cases ([3,5$\left.\left(\mathrm{CH}_{3}\right)_{2} \mathrm{C}_{6} \mathrm{H}_{3}\right]_{2}$-BIAN, 4: $\mathrm{k}_{1}=46, \mathrm{k}_{1}{ }^{\prime}=45 ; \mathrm{Ph}_{2}$-BIAN: $\mathrm{k}_{1}=149, \mathrm{k}_{1}{ }^{\prime}=144 ; 3,5-\left(\mathrm{CH}_{3}\right)_{2} \mathrm{C}_{6} \mathrm{H}_{3} ; 3,5-$ $\left.\left(\mathrm{CF}_{3}\right)_{2} \mathrm{C}_{6} \mathrm{H}_{3}-\mathrm{BIAN}, \mathbf{1}: \mathrm{k}_{1}=125, \mathrm{k}_{1}{ }^{\prime}=123\right)$, but it is acceptable even for the other two, thus validating the mathematical approach employed.

Plots of the first and second derivative of $\mathrm{CO}$ absorption of representative reactions are shown in Figures 7 and 8. Plots for all reactions are reported in the Supplementary Information (Figures S6 and S7).

Even a qualitative inspection of derivative plots reveals that more active systems deactivate more quickly and also fits that electron-withdrawing substituents give more active systems. The activity and deactivation rates of the catalyst with $\left[3,5-\left(\mathrm{CF}_{3}\right)_{2} \mathrm{C}_{6} \mathrm{H}_{3}\right]_{2}-\mathrm{BIAN}, \mathbf{5}$, as ligand, are striking. Although on a long timescale $\mathbf{5 b}$ gave the worse conversion (see Figure 3), from Figure 7 it appears that at short reaction times it affords by far the more active catalytic system, although the corresponding deactivation rate is also extremely high (Figure 8). 


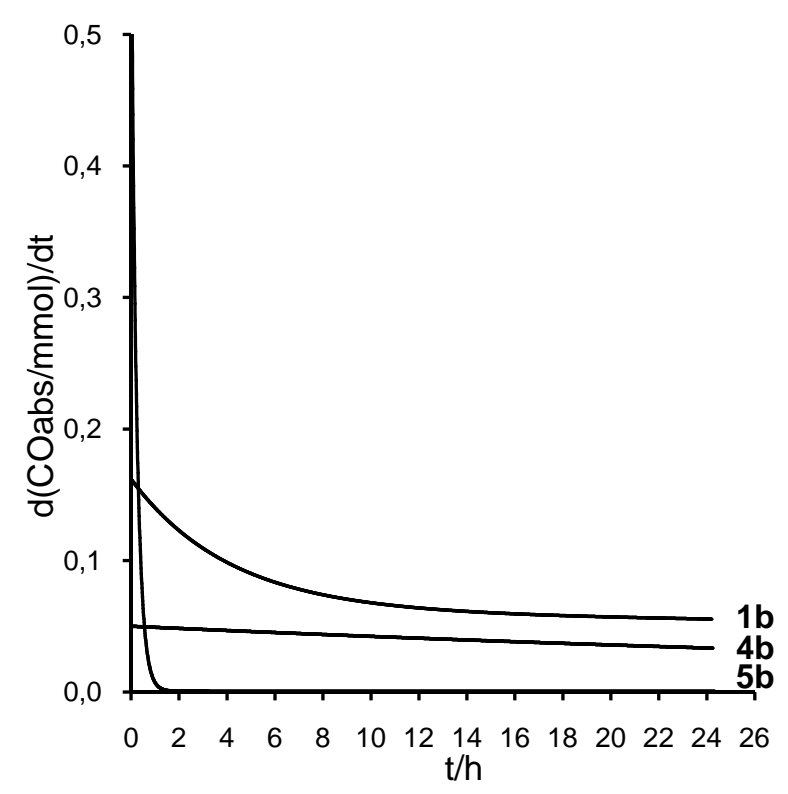

Figure 7. $1^{\text {st }}$ derivative plot for $\mathrm{CO} / 4-\mathrm{Me}$-styrene copolymerization. Catalyst precursor: $\left[\mathrm{Pd}\left(\mathrm{CH}_{3}\right)\left(\mathrm{CH}_{3} \mathrm{CN}\right)(\mathrm{Ar}-\mathrm{BIAN})\right]\left[\mathrm{PF}_{6}\right](\mathbf{1 b}, \mathbf{4 b}, \mathbf{5 b})$. Reaction conditions: see Figure 3.

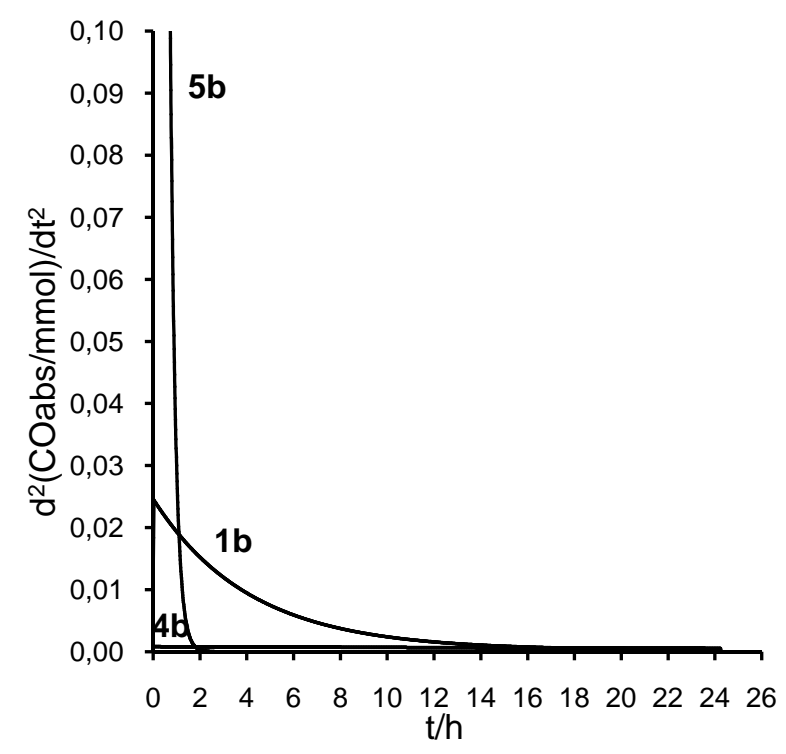

Figure 8. $2^{\text {nd }}$ derivative plot for $\mathrm{CO} / 4-\mathrm{Me}-\mathrm{styrene}$ copolymerization. Catalyst precursor: $\left[\mathrm{Pd}\left(\mathrm{CH}_{3}\right)\left(\mathrm{CH}_{3} \mathrm{CN}\right)(\mathrm{Ar}-\mathrm{BIAN})\right]\left[\mathrm{PF}_{6}\right](\mathbf{1 b}, \mathbf{4 b}, \mathbf{5 b})$. Reaction conditions: see Figure 3. 
Table 2. $\mathrm{k}_{1}$ and $\mathrm{k}_{3}$ values calculated from eq. 10 and $\mathrm{k}_{1}{ }^{\prime}$ and $\mathrm{k}_{3}{ }^{\prime}$ values calculated as deailed in the SI for reactions run with 4-Me-styrene under 5 bar $\mathrm{CO}([\mathrm{BQ}] /[\mathrm{Pd}]=5)$.

\begin{tabular}{lccccc}
\hline Ligand & $\Sigma \sigma / 2$ & $\mathrm{k}_{1} / \mathrm{h}^{-1}$ & $\mathrm{k}_{1} / \mathrm{h}^{-1}$ & $\mathrm{k}_{3} / \mathrm{h}^{-1} \mathrm{M}^{-1}$ & $\mathrm{k}_{3}{ }^{\prime} / \mathrm{h}^{-1} \mathrm{M}^{-1}$ \\
\hline$\left[3,5-\left(\mathrm{CH}_{3}\right)_{2} \mathrm{C}_{6} \mathrm{H}_{3}\right]_{2}-\mathrm{BIAN} \mathrm{(4)}$ & -0.14 & 46 & 45 & $1.27 \times 10^{2}$ & $1.33 \times 10^{2}$ \\
{$\left[3,4,5-\left(\mathrm{CH}_{3} \mathrm{O}\right)_{3} \mathrm{C}_{6} \mathrm{H}_{2}\right]_{2}$-BIAN (6) } & -0.03 & & 182 & & $7.85 \times 10^{2}$ \\
$\mathrm{Ph}_{2}$-BIAN & 0 & 149 & 144 & $2.79 \times 10^{2}$ & $2.05 \times 10^{2}$ \\
$3,5-\mathrm{F}_{2} \mathrm{C}_{6} \mathrm{H}_{3} ; 3,4,5-\left(\mathrm{CH}_{3} \mathrm{O}\right)_{3} \mathrm{C}_{6} \mathrm{H}_{2}$-BIAN (3) & 0.325 & 173 & 151 & $5.48 \times 10^{2}$ & $2.85 \times 10^{2}$ \\
$3,5-\left(\mathrm{CH}_{3}\right)_{2} \mathrm{C}_{6} \mathrm{H}_{3} ; 3,5-\left(\mathrm{CF}_{3}\right)_{2} \mathrm{C}_{6} \mathrm{H}_{3}$-BIAN (1) & 0.36 & 125 & 123 & $6.09 \times 10^{2}$ & $1.40 \times 10^{3}$ \\
$3,5-\left(\mathrm{CF}_{3}\right)_{2} \mathrm{C}_{6} \mathrm{H}_{3} ; 3,4,5-\left(\mathrm{CH}_{3} \mathrm{O}\right)_{3} \mathrm{C}_{6} \mathrm{H}_{2}$-BIAN (2) & 0.415 & 105 & 122 & $1.36 \times 10^{3}$ & $1.12 \times 10^{3}$ \\
{$\left[3,5-\mathrm{F}_{2} \mathrm{C}_{6} \mathrm{H}_{3}\right]_{2}-\mathrm{BIAN}(\mathbf{7})$} & 0.68 & & 188 & & $2.51 \times 10^{3}$ \\
{$\left[3,5-\left(\mathrm{CF}_{3}\right)_{2} \mathrm{C}_{6} \mathrm{H}_{3}\right]_{2}$-BIAN (5) } & 0.86 & & 553 & & $3.35 \times 10^{4}$ \\
\hline
\end{tabular}

In previous papers some of us have shown that the logarithm of the relative coordinating strength of substituted Ar-BIAN ligands shows a good correlation with the Hammett $\sigma$ constants. ${ }^{20,38}$ When two substituents were present, the correlation was maintained if the sum of the two individual $\sigma$ was employed, whereas ligands having different substituents on the two aryl rings followed the same trend if the arithmetic average of the Hammett $\sigma$ constants for the two rings was employed in the correlation. ${ }^{16}$ In general, this corresponds to employing for both symmetrical and nonsymmetrical ligands the value of $\Sigma \sigma / 2$ (where the sum is extended to all substituents on the two rings), which is also shown in Table 2.

A logarithmic plot of $\mathrm{k}_{1}{ }^{\prime}$ with respect to $\Sigma \sigma / 2$ is shown in Figure 9.

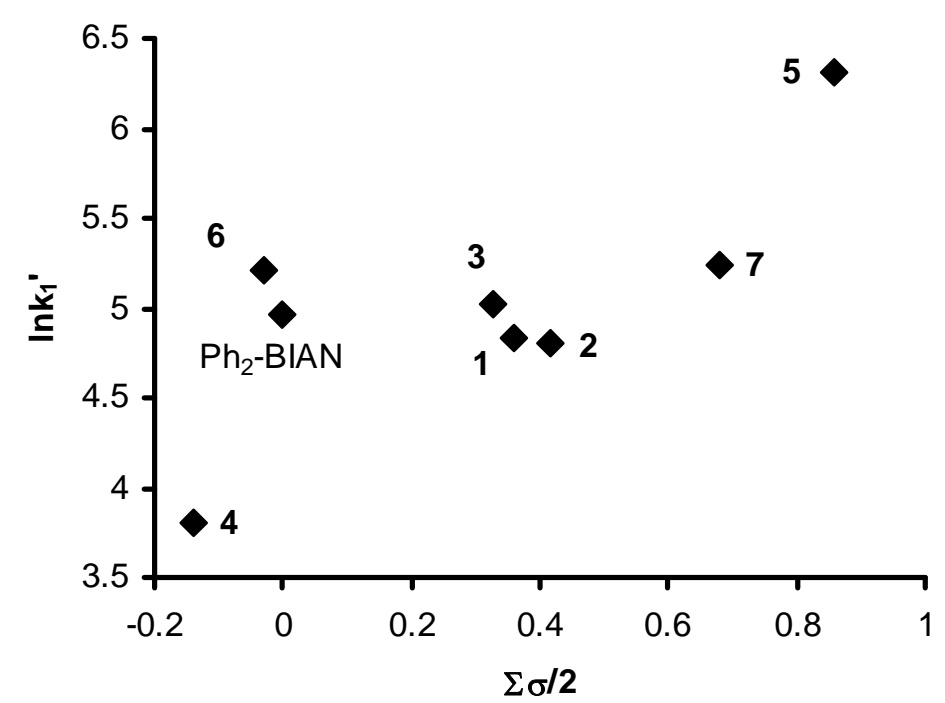

Figure 9. Plot of $\operatorname{lnk}_{1}{ }^{\prime}$ vs. $\Sigma \sigma / 2$ for the copolymerization reactions of 4-Me-styrene with $\mathrm{CO}$ (5 bar).

From the plot it appears that as a general rule electron-withdrawing groups lead to more active systems, although a clean linearity of $\operatorname{lnk}_{1}{ }^{\prime} v s . \Sigma \sigma / 2$ is not observed. 
Ligand 6 with six methoxy groups is that which deviates more strongly from the value expected based on its $\Sigma \sigma / 2$ and steric hindrance. In general, ligands having an aryl ring with three methoxy groups are those that fit less the correlation even for the reactions of unsubstituted styrene to be discussed in the following and $\left[3,4,5-\left(\mathrm{CH}_{3} \mathrm{O}\right)_{3} \mathrm{C}_{6} \mathrm{H}_{2}\right]_{2}$ - $\mathrm{BIAN}$ is that which deviates more from the correlation even with the latter substrate. It should be considered that the methoxy group has strong and opposing inductive and resonance effects and the $\Sigma \sigma$ value appears to afford a worse quantification of the electronic effects of the trimethoxyphenyl group than for other substituents. It should also be recalled that the catalytic reactions were run in trifluoroethanol, a solvent that gives strong hydrogen bonds. The methoxy oxygen is a likely donor for such hydrogen bonds and their formation would result in a decrease of the electron-donating properties of the trimethoxyphenyl group. As a matter of facts, the data for trimethoxy-substituted ligands statistically deviate from the general plot in the direction expected for a more electron-poor ligand.

The quantitative agreement between $\mathrm{k}_{3}{ }^{\prime}$ and $\mathrm{k}_{3}$ values is worse than in the case of $\mathrm{k}_{1}$, but this was expected because now even the approximations involved in the determination of the second derivative are involved. However, the trend is the same for both series of values and a logarithmic plot of $\mathrm{k}_{3}{ }^{\prime}$ vs. $\Sigma \sigma / 2$ is shown in Figure 10 (the corresponding plot of $\mathrm{k}_{3} v s$. $\Sigma \sigma / 2$ is reported in the $\mathrm{SI})$.

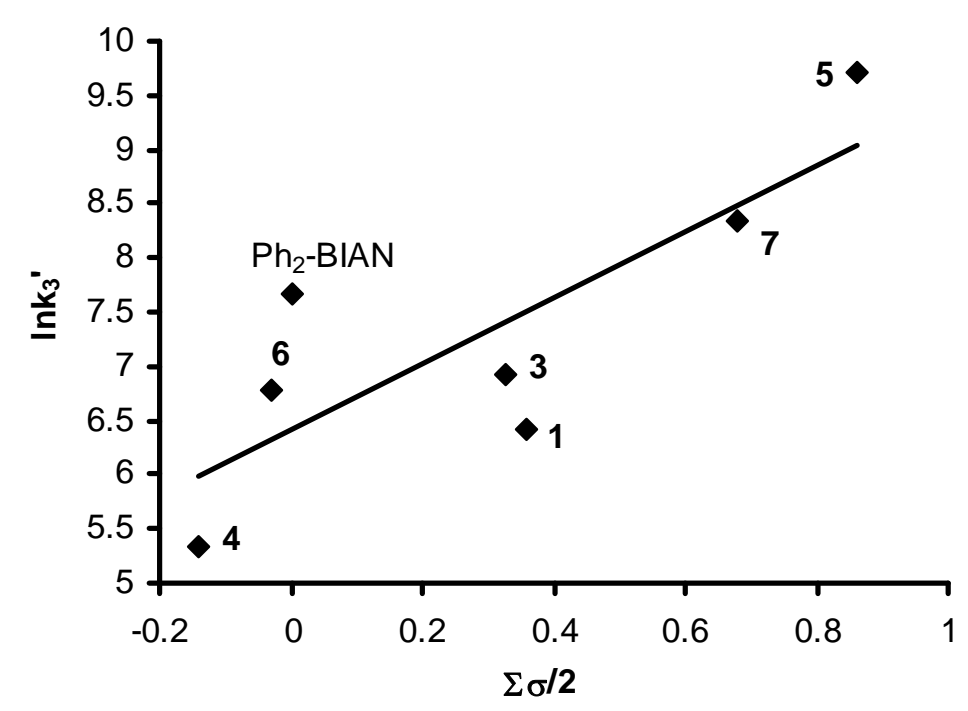

Figure 10. Plot of $\operatorname{lnk}_{3}{ }^{\prime}$ vs. $\Sigma \sigma / 2$ for the copolymerization reactions of 4-Me-styrene with $\mathrm{CO}$ (5 bar).

From the plots (Figures 10 and S4) it is evident that the presence of electron-withdrawing substituents leads to catalytic systems that deactivate at a faster rate (higher $\mathrm{k}_{3}$ and $\mathrm{k}_{3}{ }^{\prime}$ values) and 
an approximately linear correlation with $\Sigma \sigma / 2$ exists. Again the methoxy-substituted ligands are those that statistically deviate more from the correlation.

Fitting of the data of the styrene experiments run under 5 bar $\mathrm{CO}$

A series of experiments paralleling those just described, but employing unsubstituted styrene as substrate was also performed. The plots of some of the reactions were already reported in Figures 35. The plots of all reactions are reported in the Supplementary Information (Figure S10). The experiment using 3,5-( $\left(\mathrm{CF}_{3}\right)_{2} \mathrm{C}_{6} \mathrm{H}_{3} ; 3,4,5-\left(\mathrm{CH}_{3} \mathrm{O}\right)_{3} \mathrm{C}_{6} \mathrm{H}_{2}-\mathrm{BIAN}, 2$, as ligand gave some problems and has been discarded.

The data were subjected to the same mathematical treatment as described for the 4-Me-styrene reactions. Given the negative results previously obtained with the first order decomposition model, only the fit to the second order one was performed. The same three ligands that had failed to give data series that could be fitted by eq. 10 in the case of 4-Me-styrene also gave a poor fit in the present case, which leaves only four data points for which very good results were obtained. The calculated values of $\mathrm{k}_{1}$ and $\mathrm{k}_{3}$ are reported in Table 3 and graphically represented in Figures S11 and S12 (Supplementary Information).

To get information even from the remaining three reactions, the same interpolation/differentiation procedure described for 4-Me-styrene was then applied. The corresponding derivative plots are shown in Figures S13 and S14 (Supplementary Information).

From these plots, the $\mathrm{k}_{1}{ }^{\prime}$ and $\mathrm{k}_{3}{ }^{\prime}$ values can be calculated as described for the 4-Me-styrene reactions. Results are also reported in Table 3 and logarithmic plots of $\mathrm{k}_{1}{ }^{\prime}$ and $\mathrm{k}_{3}{ }^{\prime} v s . \Sigma \sigma / 2$ are shown in Figures 11 and 12, respectively. As for the case of 4-Me-styrene, only the most complete data series is discussed here, but a complete discussion of the results of the two data series can be found in the Supplementary Information.

Table 3. $\mathrm{k}_{1}$ and $\mathrm{k}_{3}$ values calculated from eq. 10 and $\mathrm{k}_{1}{ }^{\prime}$ and $\mathrm{k}_{3}{ }^{\prime}$ values calculated as detailed in the SI for reactions run with styrene under 5 bar $\mathrm{CO}([\mathrm{BQ}] /[\mathrm{Pd}]=5)$.

\begin{tabular}{lccccc}
\hline Ligand & $\Sigma \sigma / 2$ & $\mathrm{k}_{1} / \mathrm{h}^{-1}$ & $\mathrm{k}_{1} / \mathrm{h}^{-1}$ & $\mathrm{k}_{3} / \mathrm{h}^{-1} \mathrm{M}^{-1}$ & $\mathrm{k}_{3}{ }^{\prime} / \mathrm{h}^{-1} \mathrm{M}^{-1}$ \\
\hline$\left[3,5-\left(\mathrm{CH}_{3}\right)_{2} \mathrm{C}_{6} \mathrm{H}_{3}\right]_{2}$-BIAN (4) & -0.14 & 208 & 234 & $4.94 \times 10^{2}$ & $2.08 \times 10^{2}$ \\
{$\left[3,4,5-\left(\mathrm{CH}_{3} \mathrm{O}\right)_{3} \mathrm{C}_{6} \mathrm{H}_{2}\right]_{2}$-BIAN (6) } & -0.03 & & 503 & & $8.88 \times 10^{2}$ \\
$\mathrm{Ph}_{2}-\mathrm{BIAN}$ & 0 & 231 & 213 & $1.13 \times 10^{3}$ & $2.16 \times 10^{3}$ \\
$3,5-\mathrm{F}_{2} \mathrm{C}_{6} \mathrm{H}_{3} ; 3,4,5-\left(\mathrm{CH}_{3} \mathrm{O}\right)_{3} \mathrm{C}_{6} \mathrm{H}_{2}$-BIAN (3) & 0.325 & 153 & 157 & $1.11 \times 10^{3}$ & $1.01 \times 10^{3}$ \\
$3,5-\left(\mathrm{CH}_{3}\right)_{2} \mathrm{C}_{6} \mathrm{H}_{3} ; 3,5-\left(\mathrm{CF}_{3}\right)_{2} \mathrm{C}_{6} \mathrm{H}_{3}$-BIAN (1) & 0.36 & 425 & 358 & $3.05 \times 10^{3}$ & $6.09 \times 10^{2}$ \\
{$\left[3,5-\mathrm{F}_{2} \mathrm{C}_{6} \mathrm{H}_{3}\right]_{2}-\mathrm{BIAN} \mathrm{(7)}$} & 0.68 & & 85 & & $4.17 \times 10^{3}$ \\
{$\left[3,5-\left(\mathrm{CF}_{3}\right)_{2} \mathrm{C}_{6} \mathrm{H}_{3}\right]_{2}$-BIAN (5) } & 0.86 & & 422 & & $1.67 \times 10^{4}$ \\
\hline
\end{tabular}




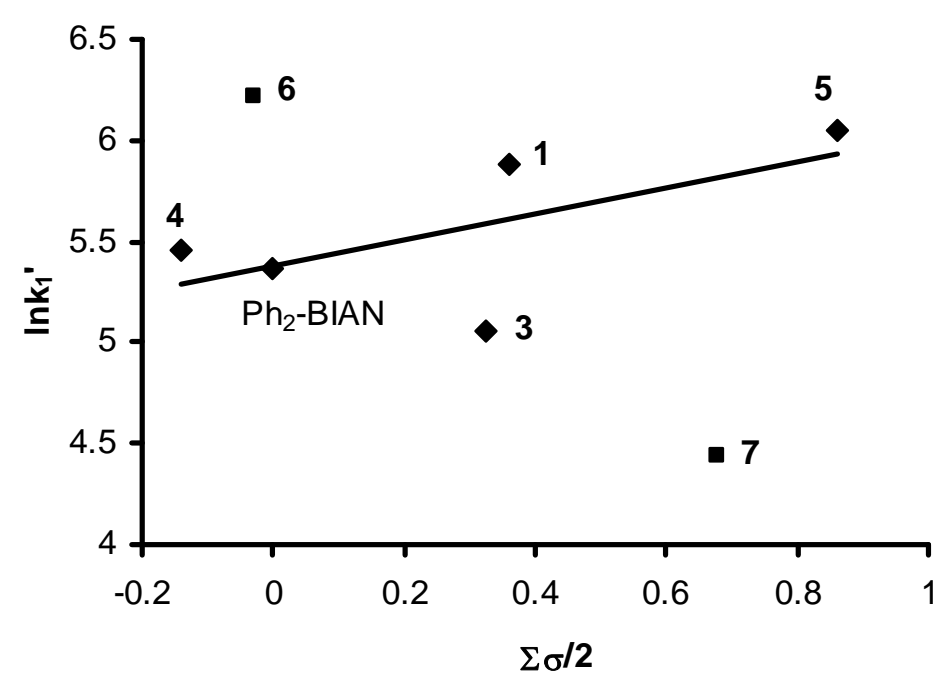

Figure 11. Plot of $\operatorname{lnk}_{1}{ }^{\prime}$ vs. $\Sigma \sigma / 2$ for the copolymerization reactions of styrene with $C O$ (5 bar). The straight line corresponds to the best fit to the data points, excluding those for $\left[3,4,5-\left(\mathrm{CH}_{3} \mathrm{O}\right)_{3} \mathrm{C}_{6} \mathrm{H}_{2}\right]_{2}-$ BIAN, 6, and $\left[3,5-\mathrm{F}_{2} \mathrm{C}_{6} \mathrm{H}_{3}\right]_{2}-\mathrm{BIAN}, 7$.

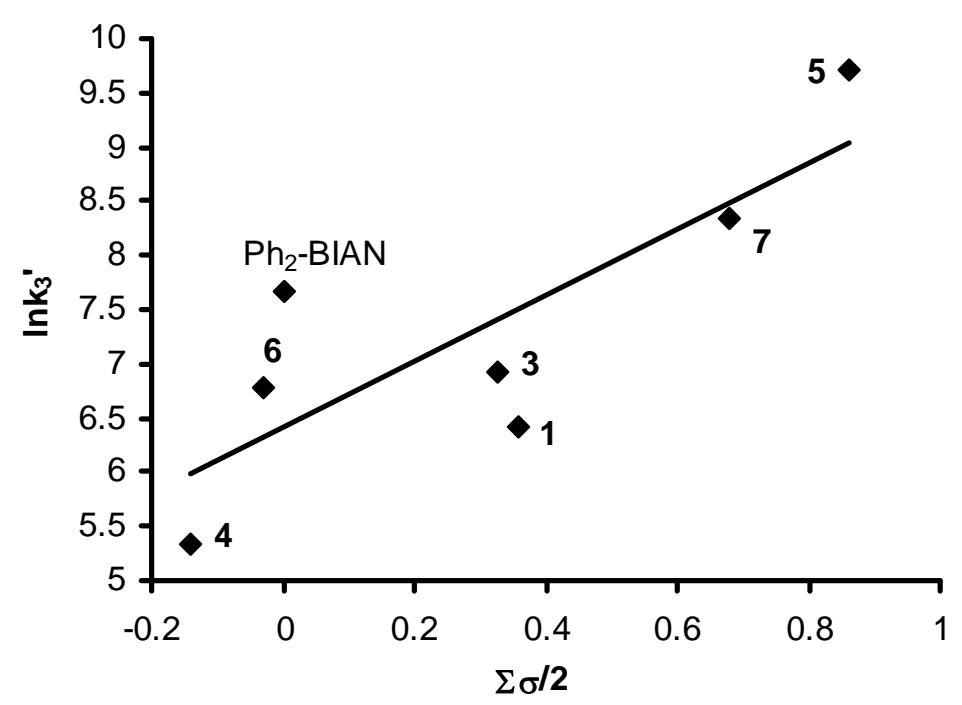

Figure 12. Plot of $\operatorname{lnk}_{3}{ }^{\prime}$ vs. $\Sigma \sigma / 2$ for the copolymerization reactions of styrene with $C O$ ( 5 bar). The straight line corresponds to the best fit to all data points.

As in the case of 4-Me-styrene, there is a good agreement between corresponding $\mathrm{k}_{1}$ and $\mathrm{k}_{1}{ }^{\prime}$ values and a worse agreement between $\mathrm{k}_{3}$ and $\mathrm{k}_{3}{ }^{\prime}$ values, but the general trends are maintained. The $\mathrm{k}_{1}{ }^{\prime}$ value for $\left[3,5-\mathrm{F}_{2} \mathrm{C}_{6} \mathrm{H}_{3}\right]_{2}-\mathrm{BIAN}, 7$, appears to be abnormally low, which may be due to extensive decomposition before the measuring of the consumed $\mathrm{CO}$ was started, as better discussed in the Supplementary Information.

In general the data follow the same trend evidenced for the 4-Me-styrene experiments, that is electron-withdrawing substituents lead to more active but less stable, catalytic systems. 
A more interesting comparison can be made between the corresponding $\mathrm{k}_{1}$ (or $\mathrm{k}_{1}{ }^{\prime}$ ) and $\mathrm{k}_{3}$ (or $\mathrm{k}_{3}{ }^{\prime}$ ) values for the two substrates. In a previous paper in which some of the same ligands employed here had been tested, it had been noted that a higher productivity was obtained with unsubstituted styrene, ${ }^{17}$ contrary to what was generally reported in the literature. ${ }^{39,40-43}$ The new, more extensive, series of data supports this observation, but also shows that the higher activity is also associated with a faster deactivation, since not only $\mathrm{k}_{1}$, but also $\mathrm{k}_{3}$ values are consistently higher in the case of styrene. To the best of our knowledge, an active role of the olefin in the deactivation process has not been proposed before. We will discuss this aspect in more detail later, after having reported the rest of the results.

The faster deactivation is responsible for the less good agreement between $k_{1}$ and $k_{1}{ }^{\prime}$ and $k_{3}$ and $k_{3}{ }^{\prime}$ values, since all approximations become larger.

\section{Effect of CO pressure}

To investigate the effect of the carbon monoxide pressure, selected reactions were performed under either 3 or 10 bar CO. The fitted values are reported in Table 4, together with the corresponding $\mathrm{k}_{1}{ }^{\prime}$ and $\mathrm{k}_{3}{ }^{\prime}$ values, calculated as in the other cases. Note that the values for the reactions at 5 bar, already reported in Table 3, are shown again here for an immediate comparison.

Table 4. $\mathrm{k}_{1}, \mathrm{k}_{1}{ }^{\prime}, \mathrm{k}_{3}$ and $\mathrm{k}_{3}{ }^{\prime}$ values for reactions run at different $\mathrm{CO}$ pressures with different ligands (styrene as substrate, $[\mathrm{BQ}] /[\mathrm{Pd}]=5$ )

\begin{tabular}{lcccc}
\hline Ligand & & 3 bar & 5 bar & 10 bar \\
\hline $3,5-\mathrm{F}_{2} \mathrm{C}_{6} \mathrm{H}_{3} ; 3,4,5-\left(\mathrm{CH}_{3} \mathrm{O}\right)_{3} \mathrm{C}_{6} \mathrm{H}_{2}-\mathrm{BIAN}$ & $\mathrm{k}_{1}$ & 77 & 153 & \\
$(\mathbf{3})$ & $\mathrm{k}_{1}{ }^{\prime}$ & 73 & 157 & 125 \\
& $\mathrm{k}_{3}$ & $3.12 \times 10^{2}$ & $1.11 \times 10^{3}$ & \\
& $\mathrm{k}_{3}^{\prime}$ & $2.16 \times 10^{2}$ & $1.01 \times 10^{3}$ & $1.03 \times 10^{3}$ \\
$3,5-\left(\mathrm{CH}_{3}\right)_{2} \mathrm{C}_{6} \mathrm{H}_{3} ; 3,5-\left(\mathrm{CF}_{3}\right)_{2} \mathrm{C}_{6} \mathrm{H}_{3}-\mathrm{BIAN}$ & $\mathrm{k}_{1}$ & 124 & 425 & \\
$(\mathbf{1})$ & $\mathrm{k}_{1}{ }^{\prime}$ & 125 & 358 & \\
& $\mathrm{k}_{3}$ & $1.07 \times 10^{3}$ & $3.05 \times 10^{3}$ & \\
& $\mathrm{k}_{3}^{\prime}$ & $3.66 \times 10^{2}$ & $6.09 \times 10^{2}$ & \\
\hline
\end{tabular}

The reactions under 5 bar are faster than those under 3 bar, but a further increase in pressure leads to a decrease in activity. ${ }^{44}$ The additional information we get from the numerical simulations is that the decrease in productivity on going to 10 bar is not due to a faster catalyst deactivation in the last case. Indeed even $k_{1}$ or $k_{1}{ }^{\prime}$ decreases at 10 bar and moreover the values of $k_{3}$ and $k_{3}{ }^{\prime}$ increase on 
going from 3 to 5 bar, but are of the same order of magnitude for reactions run at 5 or 10 bar.This indicates that the rate of deactivation is higher under 5 rather than 3 bar of $\mathrm{CO}$, but no faster deactivation takes place at higher CO pressures. Thus, the decrease in activity in the latter case is due to the inhibiting role of $\mathrm{CO}$. This is a phenomenon well known for this reaction and the value of CO pressure at which this effect becomes evident depends on the catalyst nature, if dicationic ${ }^{45}$ or monocationic ${ }^{21}$ precatalysts are applied, and on the nature of the ancillary ligand bonded to palladium. $^{21,46}$

\section{Effect of a longer reaction time and a larger amount of benzoquinone}

The effect of a longer reaction time was investigated by running selected reactions for $70 \mathrm{~h}$ instead of 25 , under 10 bar CO. Since it was expected that deactivation would occur, a higher benzoquinone amount $([\mathrm{BQ}] /[\mathrm{Pd}]=40)$ was also added (Figure 13).

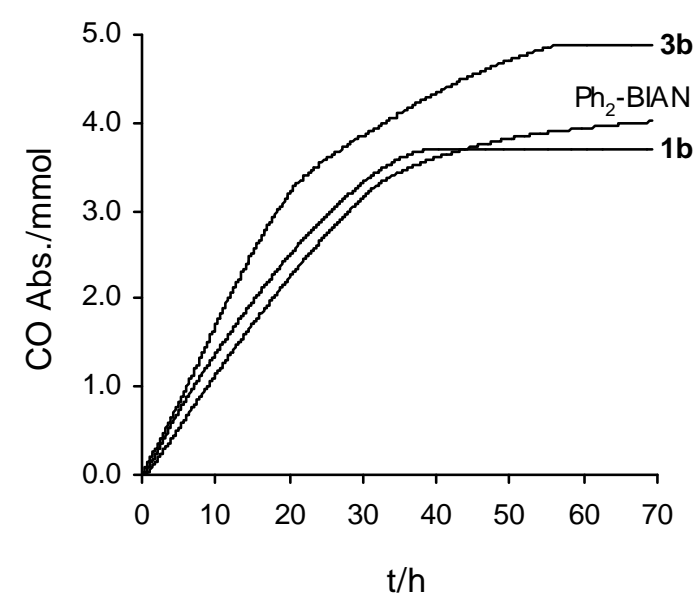

Figure 13. CO/styrene copolymerization: effect of reaction time and higher $[\mathrm{BQ}] /[\mathrm{Pd}]$ ratio. Catalyst precursor: $\left[\mathrm{Pd}\left(\mathrm{CH}_{3}\right)\left(\mathrm{CH}_{3} \mathrm{CN}\right)(\mathrm{Ar}-\mathrm{BIAN})\right]\left[\mathrm{PF}_{6}\right]$. Reaction conditions: $n_{\mathrm{Pd}}=0.106 \times 10^{-}$ ${ }^{5} \mathrm{~mol}, T=30{ }^{\circ} \mathrm{C}$, TFE $V=5 \mathrm{~mL}, P_{\mathrm{CO}}=10 \mathrm{bar}, t=70 \mathrm{~h},[\mathrm{BQ}] /[\mathrm{Pd}]=40$, styrene $V=3 \mathrm{~mL}$, $[$ styrene $] /[\mathrm{Pd}]=25000$.

From Figure 13 it is evident that the addition of a larger amount of benzoquinone strongly stabilizes the catalytic system. Deactivation is very low during the first 24 hours, contrary to what was previously observed under the same conditions, but with $[\mathrm{BQ}] /[\mathrm{Pd}]=5$. The rate decrease that is observed in all cases after about $3.2 \mathrm{mmol} \mathrm{CO}$ have been absorbed is due to the polyketone precipitation in the reaction mixture with the switch of the catalytic system from homogeneous to a mixture of homogeneous and heterogeneous species, each of them displaying its own kinetic behavior. This phenomenon was previously pointed out in both the $\mathrm{CO} /$ ethylene $^{47}$ and $\mathrm{CO} / \mathrm{vinyl}$ arene copolymerizations. ${ }^{43}$ Thus, this decrease cannot be described by our models and we have 
limited the modeling to the first $24 \mathrm{~h}$ of reaction. Due to the increased catalyst stability, good fitting by the second order deactivation mode was obtained in all cases, but in order to have a direct comparison with data with the lower benzoquinone amount, $\mathrm{k}_{1}{ }^{\prime}$ and $\mathrm{k}_{3}{ }^{\prime}$ values were also calculated. All constant values are reported in Table 5. A good agreement exists between the two calculation approaches, except for the $\mathrm{k}_{3}{ }^{\prime}$ value for $3,5-\left(\mathrm{CH}_{3}\right)_{2} \mathrm{C}_{6} \mathrm{H}_{3} ; 3,5-\left(\mathrm{CF}_{3}\right)_{2} \mathrm{C}_{6} \mathrm{H}_{3}-\mathrm{BIAN}$, which appears to be overestimated.

Table 5. Values of $\mathrm{k}_{1}, \mathrm{k}_{3}, \mathrm{k}_{1}{ }^{\prime}$ and $\mathrm{k}_{3}{ }^{\prime}$ for reactions run with styrene, under 10 bar $\mathrm{CO}$ and with $[\mathrm{BQ}] /[\mathrm{Pd}]=40$.

\begin{tabular}{lcrrrc}
\hline Ligand & $\Sigma \sigma / 2$ & $\mathrm{k}_{1} / \mathrm{h}^{-1}$ & $\mathrm{k}_{1}{ }^{\prime} / \mathrm{h}^{-1}$ & $\mathrm{k}_{3} / \mathrm{h}^{-1} \mathrm{M}^{-1}$ & $\mathrm{k}_{3}{ }^{\prime} / \mathrm{h}^{-1} \mathrm{M}^{-1}$ \\
\hline $\mathrm{Ph}_{2}$-BIAN & 0 & 125 & 124 & 107 & 92 \\
$3,5-\mathrm{F}_{2} \mathrm{C}_{6} \mathrm{H}_{3} ; 3,4,5-\left(\mathrm{CH}_{3} \mathrm{O}\right)_{3} \mathrm{C}_{6} \mathrm{H}_{2}$-BIAN (3) & 0.325 & 177 & 188 & 157 & 170 \\
$3,5-\left(\mathrm{CH}_{3}\right)_{2} \mathrm{C}_{6} \mathrm{H}_{3} ; 3,5-\left(\mathrm{CF}_{3}\right)_{2} \mathrm{C}_{6} \mathrm{H}_{3}$-BIAN (1) & 0.36 & 159 & 167 & 265 & 438 \\
\hline
\end{tabular}

Only one direct comparison can be made between reaction runs working at [BQ]/[Pd] ratio 5 and 40 respectively, but otherwise under exactly the same conditions (styrene, 10 bar $\mathrm{CO}$ ) that involving 3,5- $\mathrm{F}_{2} \mathrm{C}_{6} \mathrm{H}_{3} ; 3,4,5-\left(\mathrm{CH}_{3} \mathrm{O}\right)_{3} \mathrm{C}_{6} \mathrm{H}_{2}-\mathrm{BIAN}$. The $\mathrm{k}_{1}$ ' value marginally increased (from 125 to 188 . Values in Tables 4 and 5, respectively) upon an increase in benzoquinone amount, which may be due to the approximations in neglecting the deactivation before the gas consumption starts to be measured. However, it is $\mathrm{k}_{3}{ }^{\prime}$ that is most affected, decreasing from $1.03 \times 10^{3}$ to 170 . This variation is in agreement with the literature about the role of the oxidant that affects catalyst stability but not catalytic rate. $^{48,49}$

\section{General trends in the activity vs. time plots}

The fitting procedure allows to estimate the values of the rate constants for both the propagation step of the polymer chain and the decomposition pathway of the catalyst for the two vinyl arenes and to correlate them to the nature of the Ar-BIAN bonded to palladium (Tables 2 and 3). The CO uptake curves with time highlight that all the studied Ar-BIAN catalysts were found more active in $\mathrm{CO} /$ styrene than in $\mathrm{CO} / 4-\mathrm{Me}$-styrene copolymerization. This trend is in agreement with the productivity data obtained in the batch copolymerization reactions, ${ }^{17}$ but is the opposite of that found in the case of the phenanthroline-containing catalysts. ${ }^{21,43}$ The kinetic analysis shows that the higher activity of the present catalysts in the $\mathrm{CO} /$ styrene copolymerization is also associated with a faster deactivation, since not only $\mathrm{k}_{1}$, but also $\mathrm{k}_{3}$ values are consistently higher than in the case of 4Me-styrene (Tables 2 and 3). The values of the kinetic constants highlight that in the series of the catalysts with the symmetric Ar-BIANs, those with electron-donating substituents show the lowest 
propagation and decomposition rate, while the ligands symmetrically substituted with $\mathrm{CF}_{3}$ or $\mathrm{F}$ yield the most active catalysts, but also show the highest deactivation rate, in particular in the $\mathrm{CO} / 4-\mathrm{Me}-$ styrene copolymerization. These trends are in agreement with simple considerations about the coordination chemistry of the two comonomers: electron-donating substituents increase the electron density on palladium, disfavoring the nucleophilic attack of the alkene and increasing the $\pi$-back donation to $\mathrm{CO}$, resulting in a stronger bond to the metal center. This in turn enhances its competing role, the combination of which effects being a slow reaction rate. On the other hand ligands with electron-donating substituents are stronger bonded to palladium and, since the decomposition pathway requires ligand dissociation, the catalysts are more stable. On the contrary, electronwithdrawing substituents decrease the electron density on the metal center favoring the attack of the alkene and decreasing the $\pi$-back donation to CO. The combination of these effects being a higher reaction rate. On the other hand ligands with electron-withdrawing substituents are weaker bonded to palladium resulting in less stable catalysts. These considerations are correct from a general point of view, nevertheless, in peculiar cases the explanation is more complex. Indeed, the introduction of $\mathrm{CF}_{3}$ groups on the ancillary ligands of catalysts for polymerization was reported to result in either positive or negative effects depending on the position of the group with respect to the metal center. For instance, $\mathrm{Ni}(\mathrm{II})$ complexes with symmetrical ${ }^{\circ} \mathrm{Ar}$-BIANs substituted on one ortho position only with a $\mathrm{CF}_{3}$ group catalyzed ethylene polymerization leading to oligomers instead of polymers for steric reasons, but with higher TOF than the catalyst with the related $\mathrm{CH}_{3}$ substituted ligand for electronic effects. ${ }^{50}$ Instead, when the $\mathrm{CF}_{3}$ group is in a proper remote position of the ligand, as it is the case for nickel-phenoxyiminato catalysts, an enhancement of catalyst activity and thermal stability, and of molecular weight of produced polyethylene was observed. These effects were attributed to $\mathrm{C}-\mathrm{H}---\mathrm{F}-\mathrm{C}$ interactions between the hydrogen atom on the $\beta-\mathrm{C}$ atom of the growing polymer chain and the fluorine atom of the ligand, rather than to inductive effects. ${ }^{51}$ In the present investigation the introduction of $\mathrm{CF}_{3}$ groups on meta positions of the aryl rings has a detrimental effect on catalyst stability, despite the positive effect on catalyst activity.

This kinetic investigation highlights that among the catalysts with the nonsymmetrical ligands that with ligand $\mathbf{3}$ is the most active and the slowest to decompose for CO/4-Me-styrene.The same is valid for $\mathrm{CO} /$ styrene but in this case the catalyst with ligand $\mathbf{1}$ is more active (Tables 2 and 3). By analyzing all the data as a whole, it is clear that the catalyst with ligand $\mathbf{3}$ represents the best compromise between activity and rate of deactivation. By supposing that catalyst deactivation proceeds through ligand dissociation, the observed slow deactivation is in agreement with the higher stability of the active species thanks to the shorter Pd-N bond distances observed in solid state in the neutral palladium derivative. 


\section{Further details of the catalyst decomposition pathway}

The faster catalyst deactivation observed with ligands bearing electron-withdrawing groups may have different origins, including formation of complexes bearing two Ar-BIAN ligands and the comproportionation reaction of monomeric palladium(II) and palladium(0) complexes also having a bound ligand. However, the fact that all data point to a ligand dissociation step during the early (kinetically relevant) stages indicates that a deactivation process of the kind described should be a minor pathway during catalyst deactivation and the ligand must be lost at some stage, even if it may be regained at a later stage.

In addition, one has to take into account the positive role of benzoquinone in retarding catalyst decomposition. Benzoquinone is known to act as an oxidant towards palladium(0) complexes and the mechanism of its action has been investigated. ${ }^{52}$ In addition, complexes of the kind [(N$\mathrm{N}) \mathrm{Pd}(\mathrm{BQ})]\left(\mathrm{N}-\mathrm{N}=2,2^{\prime}\right.$-bipyridine, Ar-BIAN) are known and can be intermediates in the palladium(0) reoxidation. ${ }^{53-55}$ Oxidation even of palladium(I) dimers by benzoquinone has been considered to be a possibility, ${ }^{56}$ but, to the best of our knowledge, such a process has never been experimentally observed. The fact that catalyst deactivation follows a second order kinetics with respect to palladium suggests that such a dimer oxidation either does not occur at all or is sensibly slower than the oxidation of palladium(0) and only occurs in a few cases. Otherwise a higher order in palladium should be observed for the decomposition. Thus we will not consider palladium(I) reoxidation as a possibility in the following.

As far as ligand dissociation is concerned, we have two main alternatives. In the first (Path a in Scheme 5), the ligand is lost from a palladium(II) compound, to yield a less stabilized and more easily reducible species. The ligand ( $\mathrm{L}$ in the Scheme) substituting Ar-BIAN may be a solvent molecule, $\mathrm{CO}$ or the olefin. $\mathrm{P}$ is the growing polymer chain and may also play the role of a ligand.
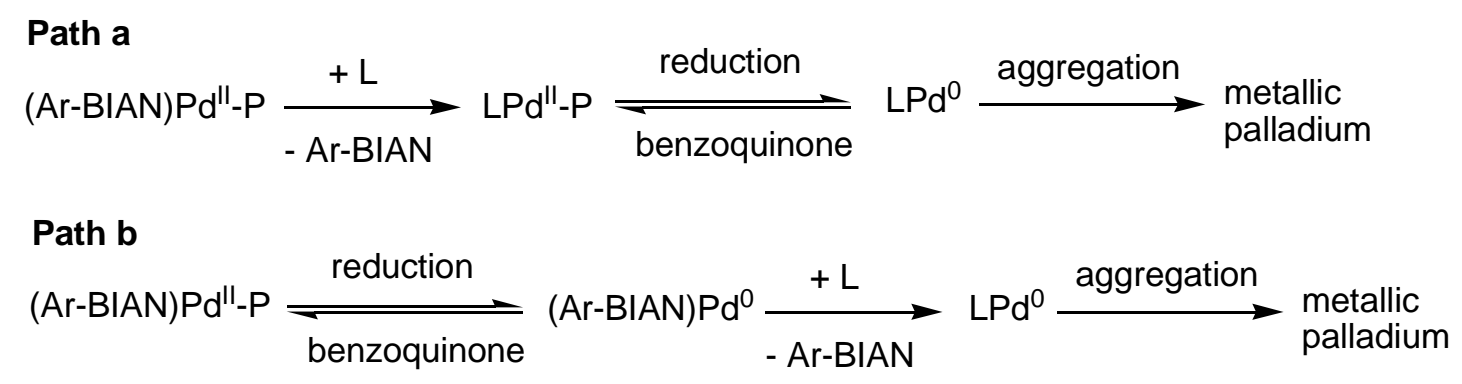

Scheme 5. Alternative pathways for ligand loss.

Alternatively, reduction can precede ligand substitution, as shown in path $b$. If this is the case, it may be advanced that ligand loss would generate a palladium(0) species that would aggregate at a rate much faster than that with which it can be reoxidized by benzoquinone. Indeed it should be 
realized that the Ar-BIAN ligand renders the complex more electron-rich, at the same time occupying two coordination sites. The first feature should favor oxidation, whereas the second should inhibit aggregation with respect to a complex lacking such a ligand.

Such a kind of alternative is present in most, if not all catalytic cycles in which palladium is involved, but we are not aware of any case in which experimental data have been provided that allow discriminating among the two. Both pathways are consistent with the kinetic data of any single reaction and cannot be distinguished looking at them independently.

At this stage we can analyze the trends in $\mathrm{k}_{3}$ or $\mathrm{k}_{3}{ }^{\prime} v s$. Hammett $\sigma$ constant on a more quantitative basis. We have already mentioned that the coordination strength of Ar-BIAN ligands is correlated with the $\sigma$ value of the substituents. ${ }^{20}$ More precisely, a linear correlation is observed between the logarithm of the equilibrium constant for the substitution of $\mathrm{Ph}_{2}-\mathrm{BIAN}$ by a generic $\left[\mathrm{RC}_{6} \mathrm{H}_{4}\right]_{2}-\mathrm{BIAN}$ and the $\sigma$ value of R. When two substituents are present, the correlation is maintained if the two $\sigma$ values are summed up. Nonsymmetrical Ar,Ar'-BIAN fitted the common plot if the average between the $\sigma$ values for the two different rings was employed in the correlation. ${ }^{16}$ What is most important to the present discussion is that the slope of these linear plots ( $\rho_{\text {BIAN }}$ ) is sensitive to the Lewis acidity of the metal fragment ${ }^{38}$ and is generally lower for complexes in which the palladium atom is zerovalent with respect to those in which it has the formal oxidation state two. The lowest sensitivity to electronic effects that could be measured $\left(\rho_{\mathrm{BIAN}}=-1.57\right.$ ) corresponds to the series $[\mathrm{Pd}(\mathrm{Ar}-\mathrm{BIAN})(\mathrm{DMFU})]$ (DMFU = dimethyl fumarate). By comparison the series $[\mathrm{Pd}(\mathrm{Ar}-$ BIAN $\left.)\left(\mathrm{CH}_{3}\right)(\mathrm{Cl})\right]$ has $\rho_{\mathrm{BIAN}}=-2.71$ and the series $\left[\mathrm{Pd}(\mathrm{Ar}-\mathrm{BIAN})\left(\mathrm{COD}-\mathrm{OCH}_{3}\right)\right]^{+}\left(\mathrm{COD}-\mathrm{OCH}_{3}\right.$ is the ligand resulting from the attack of a methoxide anion onto coordinated 1,5-cyclooctadiene), featuring a cationic palladium(II) complex similar to some complexes that are formed as intermediates in the present catalytic polymerization, has $\rho_{\mathrm{BIAN}}=-3.47$. The slope of the $\operatorname{Logk}_{3}$ or $\mathrm{k}_{3}{ }^{\prime}$ vs. Hammett $\sigma$ constant plots shown in the previous figures (once corrected for the fact that decimal logarithms are used in the calculation of $\rho_{\text {BIAN }}$ instead of natural ones) show some scatter (1.50, 1.89, 1.08, 1.31, 0.86, 1.47 respectively for the plots in Figures S4, 10 (=S9), S12, 12 (=S16), S21 and S23), as expected given the small number of data points in some cases, but the average value is 1.35 (1.15 if only the more precise $\mathrm{k}_{3}$ values are considered). The value is positive, contrary to those previously collected, but it should be remembered that now we are looking at a ligand dissociation process, whereas the previous values referred to a ligand coordination process, so that the sign is reversed. If the absolute values are compared, it clearly emerges that the present process is associated to the ligand loss from very electron-rich complexes. This clearly excludes any palladium(II) complex, especially if positively charged, and indicates that the Ar-BIAN detachment is occurring from a complex being more electron-rich than $[\operatorname{Pd}(\operatorname{Ar}-\mathrm{BIAN})(\mathrm{DMFU})]$. Given the 
compounds available in solution, by far the only likely candidates for this type of compound are $[\operatorname{Pd}(\operatorname{Ar}-B I A N)($ olefin $)]($ olefin $=$ styrene or 4 -methylstyrene $)$ or $\left[\operatorname{Pd}(\operatorname{Ar}-B I A N)(C O)_{n}\right](n=1,2)$. Palladium(0) complexes with nitrogen ligands and olefins lacking electron-withdrawing substituents have not been reported in the literature. Although, to the best of our knowledge, ligand substitution by an olefin has never been proposed as a relevant step in palladium catalysts deactivation, limited precedents exists for it. Vrieze and coworkers have reported that substituted diazabutadienes $(\mathrm{R}-\mathrm{DAB})$ could be substituted by an olefin in $\left[\mathrm{Pd}^{0}(\mathrm{R}-\mathrm{DAB})(\right.$ olefin) $\left.)\right]$ complexes ${ }^{57}$ and theoretical calculations by Elsevier and coworkers indicate that $[\operatorname{Pd}(\mathrm{R}-\mathrm{DAB})($ ethylene)] is thermodynamically unstable with respect to $\left[\mathrm{Pd}(\text { ethylene })_{3}\right]$ and R-DAB. ${ }^{58}$

It should be noted that a substitution of an Ar-BIAN ligand bound to a palladium(0) complex by an olefin as a key step in catalyst deactivation is also consistent with the observed higher instability of the catalytic system when styrene rather than 4-methylstyrene is employed as substrate. In fact it has long been known that electron-poor olefins coordinate better to palladium( 0$)$ complexes than those lacking this feature and some quantitative data on this trend have been recently gained. ${ }^{59}$ Note that exactly the opposite would be expected if Ar-BIAN loss were occurring from a palladium(II) intermediate, thus further supporting the conclusions reached.

Palladium(0) carbonyl complexes with nitrogen ligands are also unknown and only metallic palladium is invariably obtained when palladium(II) complexes with nitrogen ligands are reduced in the presence of CO. Loss of Ar-BIAN from a $\left[\mathrm{Pd}(\mathrm{Ar}-\mathrm{BIAN})(\mathrm{CO})_{\mathrm{n}}\right]$ complex is consistent with the higher $\mathrm{k}_{3}$ and $\mathrm{k}_{3}{ }^{\prime}$ measured at 5 bar $\mathrm{CO}$ with respect to those at 3 bar and may also be consistent with the $\rho_{\text {BIAN }}$ value observed, although a direct comparison with a reference compound is not available. Our data cannot distinguish between loss of the ligand from a palladium-olefin or a palladium-CO complex. The different deactivation rates observed in the case of the reactions run in styrene with respect to those run in 4-methylstyrene suggest that the former kind of complex is at least in part involved, although deactivation originating from the carbonyl complex is likely to also occur as a competitive pathway.

\section{Reactivity studies}

Catalytic and kinetic investigations show that Pd complexes containing nonsymmetrical ligands generate better performing catalysts than those with symmetrical Ar-BIANs. To get some insights about the nature of this phenomenon we investigated by means of NMR spectroscopy the reactivity of complex 1d, having the nonsymmetrical ligand 1, with both comonomers, CO and 4-Me-styrene (Scheme 6). The Pd-carbonyl-methyl complex 1d represents the active species and it was obtained in high yield as a red solid through reaction of the corresponding Pd-acyl-chloride species 1c with a 
stoichoimetric amount of NaBArF. In complex 1d, in place of the $\mathrm{PF}_{6}{ }^{-}$counterion, the less coordinating tetraarylborate is present to favor alkene insertion in the stoichiometric reactions. In turn, 1c was isolated as a dark green solid by dissolving 1a in dichloromethane previously saturated with carbon monoxide at $-20{ }^{\circ} \mathrm{C}$ (Scheme 6). It is straightforward to note that, whereas 1 a and 1d complexes are a mixture of trans and cis isomers in the ratio $10: 1$ and $3: 1$, respectively, in the NMR spectrum of $\mathbf{1 c}$ only the signals of the isomer featured by the acetyl group trans to the $\mathrm{CF}_{3^{-}}$ substituted aryl ring are observed.
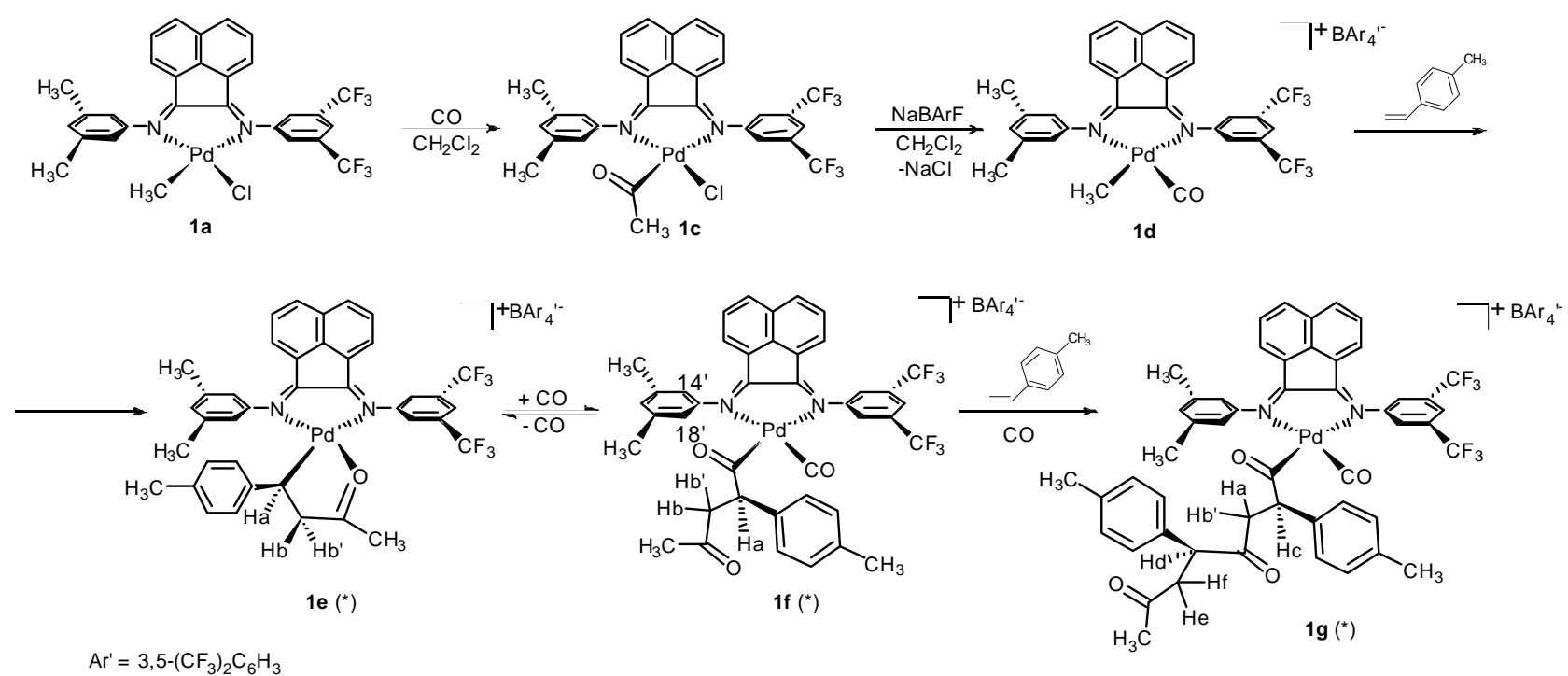

$\mathrm{Ar}=3,5-\left(\mathrm{CF}_{3}\right)_{2} \mathrm{C}_{6} \mathrm{H}_{3}$
$\left(^{*}\right)=$ only one enantiomer is shown for complexes $1 \mathbf{e}-\mathbf{1 g}$

Scheme 6. Synthesis of the active species 1d and reaction pathway for the first steps of the copolymerization reaction. While $\mathbf{1 f}$ and $\mathbf{1 g}$ have been detected, the intermediate $\mathbf{1 e}$ has been isolated.

Starting from complex 1d the intermediates resulting from the migratory insertion reactions of the two comonomers were investigated. When 1d is treated with one equivalent of 4-Me-styrene in $\mathrm{CH}_{2} \mathrm{Cl}_{2}$ at $-20{ }^{\circ} \mathrm{C}$ the five-member palladacycle 1e is obtained as a dark red solid. Analogous palladacycles were formed from the reaction of 4-Me-styrene with palladium complexes having ligands belonging to the family of phenanthrolines, ${ }^{60}$ bisoxazolines $^{42}$ and diisopropyl diazabutadiene. ${ }^{61}$ Instead, in the case of complexes with ${ }^{\circ} \mathrm{Ar}-\mathrm{BIANs}$ the reaction with 4-Me-styrene did not lead to the palladacycle, but to an intermediate involving an $\eta^{3}$-allyl bond between $\mathrm{Pd}$ and the inserted styrene unit. ${ }^{62}$ This result clearly correlates the different catalytic behavior of complexes with ortho and meta-substituted Ar-BIANs to the nature of the intermediates formed after the vinyl arene migratory insertion: when the migratory insertion leads exclusively to the $\eta^{3}$ allyl intermediate low or negligible catalytic activity is observed, while when it yields the 
palladacycle the copolymerization reaction proceeds much faster. Analogous observations were proposed to be at the origin of the inactivity of palladium complexes with diphosphine ligands (P-P) in the $\mathrm{CO} /$ vinyl arene copolymerization, in contrast to the activity of the related complexes with the phosphino-phosphite ligand BINAPHOS, leading to the metallacycle intermediate. ${ }^{63,64}$ In the latter case it was demonstrated that the CO insertion into the Pd-allyl bond is much less efficient than into the Pd-alkyl bond. ${ }^{65}$

The observation in the NMR-2D-NOESY spectrum of $1 \mathbf{e}$ of a strong cross-peak between $\mathrm{H}_{\mathrm{a}}$ of styrene unit and $\mathrm{H}_{\text {ortho }}$ of the $\mathrm{CH}_{3}$-substituted aryl ring, together with the lack of such interaction with the $\mathrm{H}_{\text {ortho }}$ of the $\mathrm{CF}_{3}$-substituted aryl ring, probes evidence that only the isomer featured by the $\mathrm{Pd}-\mathrm{C}$ bond trans to the $\mathrm{Pd}-\mathrm{N}$ bond of the $\mathrm{CF}_{3}$-substituted aryl ring is formed. This compound is the result of two migratory insertions: the migratory insertion of $\mathrm{CO}$ into the $\mathrm{Pd}-\mathrm{CH}_{3}$ bond followed by that of 4-Me-styrene into the Pd-acyl bond which takes place with secondary regiochemistry, exclusively.

In the next step the reactivity of $1 \mathrm{e}$ with $\mathrm{CO}$ was studied by bubbling the gaseous reagent into the NMR tube containing a $\mathrm{CD}_{2} \mathrm{Cl}_{2}$ solution of $1 \mathrm{e}$ at $-30{ }^{\circ} \mathrm{C}$. The complete formation of the Pd-acylcarbonyl intermediate, $\mathbf{1 f}$, was observed within $10 \mathrm{~min}$. Some relevant features of the ${ }^{1} \mathrm{H}$ NMR spectrum of $\mathbf{1 f}$ are: (i) only the signals of one species are detectable; (ii) the signal of $\mathrm{H}_{\mathrm{a}}$ is shifted from 3.51 in $\mathbf{1 e}$ to $4.61 \mathrm{ppm}$ in $\mathbf{1 f}$ due to the deshielding effect of the adjacent $\mathrm{CO}$ group; (iii) in the 2D-NOESY spectrum a cross-peak is present between $\mathrm{H}_{\mathrm{a}}$ and $\mathrm{H}^{14^{\prime}, 18^{\prime}}$; (iv) the resonances of protons $\mathrm{H}_{\mathrm{b}, \mathrm{b}^{\prime}}$ of the $\mathrm{CH}-\mathrm{CH}_{2}$ fragment do not exhibit a diamagnetic shift of the type that was observed in the case of the complexes with ${ }^{\circ} \mathrm{Ar}-\mathrm{BIANs}$, suggesting that the $\mathrm{CH}_{2}$ group in the present case is not inside the shielding cone of the aromatic ring of the ligand; (v) two signals are observed for the methyl groups of the aryl ring, while in complexes 1a - 1e only one singlet was observed, indicating that in $\mathbf{1 f}$ the rotation of the aryl ring is hindered. This NMR analysis shows that $\mathbf{1 f}$ is the Pd-acyl-carbonyl species with the growing polymer chain oriented towards the $\mathrm{CH}_{3}$-substituted aryl ring (Scheme 6).

The solution of $\mathbf{1 f}$ was treated with 1 equivalent of 4-Me-styrene under CO atmosphere. After 4 days at $-18^{\circ} \mathrm{C}$ no signal of $\mathbf{1 f}$ and free vinyl arene are present, while the signals of the new species $\mathbf{1 g}$ are observed. The complexity of the ${ }^{1} \mathrm{H}$ NMR spectrum of the double olefin insertion product $\mathbf{1 g}$ suggests the presence of two diastereoisomeric complexes with a $R R$ and $R S$ (or $S S$ and $S R$ ) configuration of the $\mathrm{CH}-\mathrm{Ph}$ stereogenic centers, corresponding to like and unlike dyads in the polymeric chain. This result is in agreement with the atactic stereochemistry of the synthesized polyketones and indicates that no enantioface discrimination takes place since the insertion of the second molecule of vinyl arene. Finally, in the spectrum of $\mathbf{1 g}$ the region of the signals of the 
aromatic protons is crowded due to the signals of the two inserted 4-methylstyrene molecules, thus the NOE experiments are not a clear cut as it was for $\mathbf{1 f}$ in indicating that the growing polymer chain is trans to the $\mathrm{CF}_{3}$-substituted aryl ring.

Thanks to this NMR investigation it was possible to detect the intermediates formed at the beginning of the copolymerization reaction and to demonstrate that when the ancillary ligands are nonsymmetrical molecules there is a preferential coordination site for the growing polymer chain, that is trans to the $\mathrm{N}$ atom with lowest Lewis basicity. Thus, each time this is not the isomer resulting from the migratory insertion, an isomerization process takes place before the next insertion reaction to proceed. For the present complexes there is a site selective coordination of the growing polymer chain. This phenomenon is well known as back-skip in the catalytic synthesis of isotactic polypropene. ${ }^{66}$ In the case of $\mathrm{CO} /$ alkene copolymerization the site selective coordination of the alkene was observed for both palladium complexes with amine-imine ligands, ${ }^{27}$ with hybrid P-N ligands $^{48}$ and with the phosphino-phosphite (P-PO) molecule BINAPHOS. ${ }^{67} \mathrm{~A}$ mechanistic hypothesis involving cis/trans isomerization was invoked.

Very recently both in the polyethylene synthesis and in the ethylene/methyl acrylate copolymerization catalyzed by $\mathrm{Pd}$-complexes with phosphino-sulfonate $(\mathrm{P}-\mathrm{O})$ ligands the cis/trans isomerization was indicated as an important step of the catalytic cycle. ${ }^{68,69}$ In all the mentioned examples the preferential polymer chain coordination site is determined by an electronic differentiation of the two donor atoms, i.e. hard and soft for the $\mathrm{P}-\mathrm{O}$ and $\mathrm{N}_{\mathrm{sp} 3}-\mathrm{N}_{\mathrm{sp} 2}$ ligands, or trans influence in the hybrid P-N catalysts. For the catalysts with the bis(imine) Ar-BIANs, topic of the present investigation, the difference in the electronic features of the two N-donor atoms should be less pronounced than that in the other two series. Nevertheless, it appears to be sufficient to drive the preferential coordination of the polymer chain.

\section{Conclusions}

Palladium complexes with $\alpha$-diimine ligands having an acenaphthene skeleton and aryl rings on the imine nitrogen atoms have been widely applied as homogeneous catalysts for (co)polymerization reactions. In the past we demonstrated that up to now the best performing catalysts within this ligand family, both in the CO/vinyl arene and ethylene/methyl acrylate copolymerization, are featured by nonsymmetrically substituted Ar,Ar'-BIANs. The library of the Ar,Ar'-BIANs has been now extended to a new molecule featured by a meta-F-substituted aryl ring and a meta,paramethoxy-substituted ring.

The kinetic study together with its modelization reported in this paper allows to quantitatively distinguish between catalyst activity and its decomposition rate and to mainly correlate them to the 
electronic properties of the substituents on the aryl rings. Catalysts having symmetrical Ar-BIANs substituted with electron-donating groups show the lowest propagation and decomposition rate; whereas those having symmetrical Ar-BIANs substituted with electron-withdrawing groups yield the most active catalysts, but with the highest deactivation rate. Thus, the best performing catalysts are those with the nonsymmetrical Ar,Ar'-BIANs and, among them, the active species with the new ligand 3 represents the best compromise between activity and rate of deactivation.

When studying a catalytic system one usually tries to employ experimental conditions that minimize catalyst decomposition and quantitative kinetic studies are usually performed only under conditions in which decomposition is negligible. In this work we have quantitatively investigated the behavior of a series of catalysts that deactivate to a variable and sometime high extent. This allowed us to gain important information on the catalyst deactivation pathways, which are probably much more general. The deactivation was shown to involve the following steps:

1) Palladium reduction from +2 to zero oxidation state. This step can be reverted easily by reaction with benzoquinone;

2) Chelating ligand loss, likely by displacement by the olefin or CO. Reoxidation after ligand dissociation appears not to compete effectively with the next step in the deactivation;

3) The resulting palladium(0) complex reacts with another palladium(II) unit to generate a palladium(I) dimer that cannot be oxidized back under the reaction conditions and either accumulates or irreversibly evolves towards metallic palladium.

These results suggest two strategies to increase catalyst life. Since ligand loss is an equilibrium reaction, this should be shifted to the reactants side by adding an excess of free nitrogen ligand in solution, resulting in catalyst stabilization. In addition, if ligand loss is favored by simultaneous olefin coordination, decreasing olefin concentration may also result in a more stable catalytic system, although activity may also decrease. These strategies will be investigated in the future and will be the topic of a future work.

\section{Experimental}

\section{Materials and methods}

$\left[\mathrm{Pd}(\mathrm{OAc})_{2}\right]$ was a gift from Engelhard Italia and was used as received. All the solvents were purchased from Sigma-Aldrich and used without further purification for synthetic, spectroscopic and catalytic purposes, with the only exception of the dichloromethane used for the synthesis of complexes, which was purified through distillation over $\mathrm{CaH}_{2}$ under argon atmosphere and used freshly distilled. Carbon monoxide (grade 4.7) was supplied by Linde Gasfor kinetic investigations and by Air Liquide (CP grade $99.99 \%$ ) for mechanistic studies. NMR spectra of ligands and 
complexes were recorded on a Jeol EX 400 and a Varian 500 spectrometer at $298 \mathrm{~K}$ and at 400 and $500 \mathrm{MHz}$, respectively; NMR studies for mechanistic investigations were performed on a BrukerAC200 spectrometer. The resonances were referenced to the solvent peak versus TMS: $\mathrm{CDCl}_{3}$ at $\delta$ $7.26\left({ }^{1} \mathrm{H}\right)$ and $\delta 77.0\left({ }^{13} \mathrm{C}\right), \mathrm{CD}_{2} \mathrm{Cl}_{2}$ at $\delta 5.32\left({ }^{1} \mathrm{H}\right) .{ }^{13} \mathrm{C}$ NMR spectra of polyketones were recorded in 1,1,1,3,3,3-hexafluoro-2-propanol (HFIP) with a small amount of $\mathrm{CDCl}_{3}$ for locking purposes at 125.68 $\mathrm{MHz}$ and referenced at $\delta$ 77.0. IR spectra of monocationic complexes were recorded in Nujol on a Perkin Elmer System 2000 FT-IR.

NMR spectra for ligands 3 and 7 were recorded on Bruker Avance 300-DRX or Avance 400-DRX spectrometers. Chemical shifts (ppm) are reported relative to TMS. The ${ }^{1} \mathrm{H}$ NMR signals of the compounds described in the following have been attributed by COSY and NOESY techniques. Assignments of the resonance in ${ }^{13} \mathrm{C}$ NMR were made using the APT pulse sequence and HSQC and HMBC techniques. CAUTION: when NMR spectra of Ar-BIAN ligands containing electronwithdrawing substituents are recorded in $\mathrm{CDCl}_{3}$, it is essential that the solvent is purified by passing it over a short column of basic alumina to eliminate acidic impurities. Otherwise, partial hydrolysis of the ligand is observed.

Ligands 1, 2, 4-6 and the related palladium complexes were synthesized following literature procedures. $^{17,19-21,38}$

\section{Synthesis of Ligands 3 and 7}

Ligand 3. The procedure is adapted from ref. 38. To a Schlenk flask were added $\mathrm{ZnCl}_{2}\left(3,5-\mathrm{F}_{2} \mathrm{C}_{6} \mathrm{H}_{3}-\right.$ BIAN), obtained as described below (0.500 g, $0.93 \mathrm{mmol}), 3,4,5$-trimethoxyaniline (174.0 mg, 0.95 $\mathrm{mmol})$, and dry methanol $(60 \mathrm{~mL})$. The suspension was stirred under dinitrogen for 2 hours, then it was evaporated in vacuo and the obtained solid was washed with a hexane/toluene 1:1 mixture (10 $\mathrm{mL})$. The remained solid was dissolved in dichloromethane $(25 \mathrm{~mL})$ in a separating funnel and decomplexed by shaking with a saturated solution of potassium oxalate $(10 \mathrm{~mL})$. The organic layer was separated and washed with water $(3 \times 10 \mathrm{~mL})$. The organic layer was then dried over sodium sulfate, filtered and evaporated in vacuo. The products was purified by column chromatography on silica (eluent hexane/triethylamine 9.5:0.5). The nonsymmetrical ligand was eluted first (220 mg, 52 $\%$ yield), followed by some $\left[3,4,5-\left(\mathrm{CH}_{3} \mathrm{O}\right)_{3} \mathrm{C}_{6} \mathrm{H}_{2}\right]_{2}$-BIAN.

Elemental analysis: C, 70.74; H, 4.40; N, 6.11. Found: C, 70.51; H, 4.50; N, 6.09.

$\delta_{\mathrm{H}}\left(400 \mathrm{MHz} ; \mathrm{CDCl}_{3}, 298 \mathrm{~K}\right), 7.98\left(\mathrm{~d}, J=8.2 \mathrm{~Hz}, 1 \mathrm{H}, \mathrm{H}^{5}\right.$ or $\left.\mathrm{H}^{8}\right), 7.96\left(\mathrm{~d}, J=8.2 \mathrm{~Hz}, 1 \mathrm{H}, \mathrm{H}^{8}\right.$ or $\left.\mathrm{H}^{5}\right)$, 7.47 (pst, $\left.J=7.8 \mathrm{~Hz}, 2 \mathrm{H}, \mathrm{H}^{4}, \mathrm{H}^{9}\right), 7.14\left(\mathrm{~d}, J=7.3 \mathrm{~Hz}, 1 \mathrm{H}, \mathrm{H}^{10}\right), 6.99\left(\mathrm{~d}, J=7.2 \mathrm{~Hz}, 1 \mathrm{H}, \mathrm{H}^{3}\right), 6.72$ (pst, $\left.J=9.0 \mathrm{~Hz}, 1 \mathrm{H}, \mathrm{H}^{16}\right), 6.66\left(\mathrm{~d}, J=8.0 \mathrm{~Hz}, 2 \mathrm{H}, \mathrm{H}^{14}, \mathrm{H}^{18}\right), 6.38\left(\mathrm{~s}, 2 \mathrm{H}, \mathrm{H}^{14^{\prime}}, \mathrm{H}^{18^{\prime}}\right), 3.94(\mathrm{~s}, 3 \mathrm{H}, p$ $\left.\mathrm{OCH}_{3}\right), 3.83\left(\mathrm{~s}, 6 \mathrm{H}, \mathrm{m}-\mathrm{OCH}_{3}\right) . \delta_{\mathrm{C}}\left(75 \mathrm{MHz}, \mathrm{CDCl}_{3}, 298 \mathrm{~K}\right) 162.7\left(\mathrm{C}^{1,12}\right), 154.7\left(\mathrm{C}^{15^{\prime}, 17}\right), 147.7\left(\mathrm{C}^{13}\right.$ 
or $\left.\mathrm{C}^{7}\right), 131.7\left(\mathrm{C}^{6}\right), 130.2\left(\mathrm{C}^{5}\right.$ or $\left.\mathrm{C}^{8}\right), 129.7\left(\mathrm{C}^{5}\right.$ or $\left.\mathrm{C}^{8}\right), 128.4\left(\mathrm{C}^{4}\right.$ or $\left.\mathrm{C}^{9}\right), 128.2\left(\mathrm{C}^{4}\right.$ or $\left.\mathrm{C}^{9}\right), 124.8\left(\mathrm{C}^{10}\right)$, $124.5\left(\mathrm{C}^{3}\right), 102.1\left(\mathrm{~d}, J_{\mathrm{C}-\mathrm{F}}^{2}=27.0 \mathrm{~Hz}, \mathrm{C}^{14,18}\right), 99.9\left(\mathrm{C}^{16}\right), 95.8\left(\mathrm{C}^{\prime} 4^{\prime}, 18^{\prime}\right), 61.62\left(p-\mathrm{OCH}_{3}\right), 56.6(m-$ $\left.\mathrm{OCH}_{3}\right)$. Eight quaternary carbons were not detected. ${ }^{19} \mathrm{~F}\left\{{ }^{1} \mathrm{H}\right\} \mathrm{NMR}\left(376 \mathrm{MHz}, \mathrm{CDCl}_{3}, 298 \mathrm{~K}\right), \delta$, ppm, -108.2 (s, F).

Ligand 7. The procedure is adapted from ref. 20. To a Schlenk flask under a dinitrogen atmosphere were added acenaphthenequinone (313.0 mg, $1.72 \mathrm{mmol})$, dry $\mathrm{ZnCl}_{2}(606.5 \mathrm{mg}, 4.45 \mathrm{mmol})$, and $\mathrm{AcOH}(4.7 \mathrm{~mL})$. The suspension was heated to about $50-60{ }^{\circ} \mathrm{C}$ and the $3,5-\mathrm{F}_{2} \mathrm{C}_{6} \mathrm{H}_{3} \mathrm{NH}_{2}(521.6 \mathrm{mg}$, $4.04 \mathrm{mmol}$ ) mmol) was then added. The solution was reflux heated for $45^{\prime}$ and then filtered on a Büchner funnel while hot. The solid was washed on the filter with diethyl ether to help remove the acetic acid and dried in vacuo to give $\mathrm{ZnCl}_{2}$ (7) $(733.3 \mathrm{mg}, 1.36 \mathrm{mmol}, 79.1 \%$ yield). Care must be taken to eliminate any residue of the acetic acid employed as solvent in the synthesis, as this has a strongly negative effect on the effectiveness of the separation in the following step. Note also that the addition of toluene to the solution mixture is generally required when anilines bearing trifluoromethyl groups are employed, to make precipitation of the complex easier. ${ }^{20} \mathrm{However}$, with difluoroaniline this addition was not necessary.

$\mathrm{ZnCl}_{2}$ (7) $(717.1 \mathrm{mg}, 1.33 \mathrm{mmol})$ was then placed in a flask in the air and suspended in $\mathrm{CH}_{2} \mathrm{Cl}_{2}(65$ $\mathrm{mL})$. A solution of $\mathrm{K}_{2} \mathrm{C}_{2} \mathrm{O}_{4}(1.48 \mathrm{~g}, 8.14 \mathrm{mmol})$ in water $(9 \mathrm{~mL})$ was then added and the biphasic mixture vigorously stirred for $15 \mathrm{~min}$. The phases were separated and the organic layer was washed with water $(2 \times 10 \mathrm{~mL})$, dried with $\mathrm{Na}_{2} \mathrm{SO}_{4}$, filtered and evaporated to dryness affording the analytically pure 7 ( $456.7 \mathrm{mg}, 1.13 \mathrm{mmol}, 85.0 \%$ yield).

Elemental analysis: $\mathrm{C}, 71.30 ; \mathrm{H}, 2.99 ; \mathrm{N}, 6.93$. Found: $\mathrm{C}, 71.12 ; \mathrm{H}, 3.15 ; \mathrm{N}, 6.84$.

$\delta_{\mathrm{H}}\left(400 \mathrm{MHz} ; \mathrm{CDCl}_{3}, 298 \mathrm{~K}\right) 7.99\left(2 \mathrm{H}, \mathrm{d}, J_{\mathrm{H}-\mathrm{H}}=8.3 \mathrm{~Hz}, \mathrm{H}^{5,8}\right), 7.50\left(2 \mathrm{H}, \mathrm{pt}, J_{\mathrm{H}-\mathrm{H}}=7.5 \mathrm{~Hz}, \mathrm{H}^{4,9}\right), 7.05$ $\left(2 \mathrm{H}, \mathrm{d}, J_{\mathrm{H}-\mathrm{H}}=7.2 \mathrm{~Hz}, \mathrm{H}^{3,10}\right), 6.73\left(2 \mathrm{H}, \mathrm{tt}, J_{\mathrm{H}-\mathrm{F}}=9.0 \mathrm{~Hz}, J_{\mathrm{H}-\mathrm{H}}=2.2 \mathrm{~Hz}, \mathrm{H}^{16}\right), 6.67\left(4 \mathrm{H}, \mathrm{dd}, J_{\mathrm{H}-\mathrm{F}}=7.9\right.$ $\left.\mathrm{Hz}, J_{\mathrm{H}-\mathrm{H}}=2.2 \mathrm{~Hz}, \mathrm{H}^{14,18}\right)$ ppm. $\delta_{\mathrm{C}}\left(100 \mathrm{MHz}, \mathrm{CDCl}_{3}, 298 \mathrm{~K}\right) 169.9\left(\mathrm{dd}, J^{1}{ }_{\mathrm{C}-\mathrm{F}}=247.2, J_{\mathrm{C}-\mathrm{F}}^{3}=1.4 \mathrm{~Hz}\right.$, $\left.\mathrm{C}^{15,17}\right), 161.7\left(\mathrm{C}^{1,12}\right), 153.8\left(\mathrm{~d}, J_{\mathrm{C}-\mathrm{F}}^{3}=1.2 \mathrm{~Hz}, \mathrm{C}^{13}\right), 142.1\left(\mathrm{C}^{7}\right), 131.4\left(\mathrm{C}^{6}\right), 129.9\left(\mathrm{C}^{5,6}\right), 127.6$ $\left(\mathrm{C}^{2,11}\right), 123.9\left(\mathrm{C}^{3,10}\right), 101.7\left(\mathrm{dd}, J^{2}{ }_{\mathrm{C}-\mathrm{F}}=19.4, J_{\mathrm{C}-\mathrm{F}}^{4}=7.4 \mathrm{~Hz}, \mathrm{C}^{14,18}\right), 99.7\left(\mathrm{~d}, J_{\mathrm{C}-\mathrm{F}}^{2}=25.4 \mathrm{~Hz}, \mathrm{C}^{16}\right) . \delta_{\mathrm{F}}$ $\left(376 \mathrm{MHz} ; \mathrm{CDCl}_{3}, 298 \mathrm{~K}\right)-108.4$ (pt, $J=8.0 \mathrm{~Hz}$ ).

\section{Synthesis of Pd Complexes.}

All syntheses were performed using standard vacuum-line and Schlenk techniques under argon atmosphere and at room temperature, according to the published procedures..$^{19,21}$

[Pd( $\left.\left.\mathrm{CH}_{3}\right) \mathbf{C l}(\mathrm{Ar}-\mathrm{BIAN})\right](\mathbf{3 a}, \mathbf{7 a})$

General synthesis. $\left[\mathrm{Pd}\left(\mathrm{CH}_{3}\right) \mathrm{Cl}(\mathrm{cod})\right](201.5 \mathrm{mg}, 0.76 \mathrm{mmol})$ was kept in a Schlenk flask and dissolved in $\mathrm{CH}_{2} \mathrm{Cl}_{2}(3 \mathrm{~mL})$. A solution of the ligand $(0.84 \mathrm{mmol})$ in $\mathrm{CH}_{2} \mathrm{Cl}_{2}(3 \mathrm{~mL})$ was added. 
The reaction mixture was protected from light, stirred at r.t. for $1 \mathrm{~h}$, and then concentrated at half volume under reduced pressure. Upon addition of diethyl ether a red solid was obtained.

[Pd( $\left.\left.\mathbf{C H}_{\mathbf{3}}\right) \mathbf{C l}(\mathbf{3})\right]$ (3a)Yield: $89 \%$. Dark red solid.

Elemental analysis: C, 54.65; H, 3.77; N, 4.55. Found: C, 54.76; H, 3.83; N, 4.75.

$\delta_{\mathrm{H}}\left(400 \mathrm{MHz} ; \mathrm{CD}_{2} \mathrm{Cl}_{2} ; 298 \mathrm{~K} ; \mathrm{M}=\right.$ major, $\mathrm{m}=$ minor) 8.19-8.10 (m, $\left.\mathrm{H}^{5,8}{ }_{\mathrm{M}, \mathrm{m}}\right), 7.59-7.51(\mathrm{~m}$, $\left.\mathrm{H}^{4,9}{ }_{\mathrm{M}, \mathrm{m}}\right), 7.46\left(1 \mathrm{H}, \mathrm{d}, \mathrm{H}^{10}{ }_{\mathrm{m}}\right), 7.25\left(1 \mathrm{H}, \mathrm{d}, \mathrm{H}^{3}{ }_{\mathrm{M}}\right), 6.93-6.84\left(\mathrm{~m}, \mathrm{H}^{14,16,18}{ }_{\mathrm{M}, \mathrm{m}}\right.$ and $\left.\mathrm{H}^{10}{ }_{\mathrm{M}}\right), 6.79(1 \mathrm{H}, \mathrm{d}$, $\left.\mathrm{H}_{\mathrm{m}}^{3}\right), 6.66\left(2 \mathrm{H}, \mathrm{s}, \mathrm{H}^{14^{\prime}, 18^{\prime}} \mathrm{m}\right), 6.49\left(2 \mathrm{H}, \mathrm{s}, \mathrm{H}^{14^{\prime}, 18^{\prime}}{ }_{\mathrm{M}}\right), 3.89\left(\mathrm{~s},{ }^{p} \mathrm{OCH}_{3, \mathrm{M}, \mathrm{m}}\right), 3.84\left(\mathrm{~s},{ }^{m} \mathrm{OCH}_{3, \mathrm{M}, \mathrm{m}}\right), 0.91$ $\left(3 \mathrm{H}, \mathrm{s}, \mathrm{Pd}-\mathrm{CH}_{3, \mathrm{M}}\right), 0.80\left(3 \mathrm{H}, \mathrm{s}, \mathrm{Pd}-\mathrm{CH}_{3, \mathrm{~m}}\right)$.

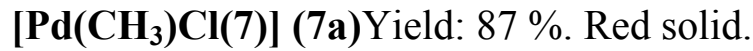

Elemental analysis: C, 53.50; H, 2.69; N, 4.99. Found: C, 53.90; H, 2.58; N, 4.98.

$\delta_{\mathrm{H}}\left(500 \mathrm{MHz} ; \mathrm{CD}_{2} \mathrm{Cl}_{2} ; 298 \mathrm{~K}\right) 8.18\left(2 \mathrm{H}, \mathrm{m}, \mathrm{H}^{5,8}\right), 7.58\left(2 \mathrm{H}, \mathrm{m}, \mathrm{H}^{4,9}\right), 7.28\left(1 \mathrm{H}, \mathrm{d}, \mathrm{H}^{3}\right), 7.01-6.83$ $\left(7 \mathrm{H}, \mathrm{m}, \mathrm{H}^{14,14^{\prime}, 16,16^{\prime}, 18,18^{\prime}, 10}\right) 0.85\left(3 \mathrm{H}, \mathrm{s}, \mathrm{Pd}-\mathrm{CH}_{3}\right)$.

\section{$\left[\mathrm{Pd}\left(\mathrm{CH}_{3}\right)\left(\mathrm{CH}_{3} \mathrm{CN}\right)(\mathrm{Ar}-\mathrm{BIAN})\right]\left[\mathrm{PF}_{6}\right](3 \mathrm{~b}, 7 \mathrm{~b})$}

General synthesis.A solution of $\mathrm{AgPF}_{6}(0.401 \mathrm{mmol})$ in $\mathrm{CH}_{3} \mathrm{CN}(1 \mathrm{~mL})$ was added to a solution of the neutral complex $(0.349 \mathrm{mmol})$ in $\mathrm{CH}_{2} \mathrm{Cl}_{2}(2 \mathrm{~mL})$. The solution was stirred at r.t. for $30 \mathrm{~min}$, then $\mathrm{AgCl}$ was filtered over celite; the solution was then concentrated to half volume under vacuum. Upon addition of diethyl ether the product precipitated as a solid.

[Pd( $\left.\left.\mathbf{C H}_{3}\right)\left(\mathbf{C H}_{3} \mathbf{C N}\right)(3)\right]\left[\mathbf{P F}_{6}\right] \mathbf{( 3 b ) Y i e l d : ~} 77$ \%. Orange solid.

$\delta_{\mathrm{H}}\left(400 \mathrm{MHz} ; \mathrm{CD}_{2} \mathrm{Cl}_{2} ; 298 \mathrm{~K} ; \mathrm{M}=\right.$ major, $\mathrm{m}=$ minor) 8.25-8.19 (2H, m, $\left.\mathrm{H}^{5,8}{ }_{\mathrm{M}, \mathrm{m}}\right), 7.66-7.57(\mathrm{~m}$, $\left.\mathrm{H}^{4,9}{ }_{\mathrm{M}, \mathrm{m}}\right), 7.47\left(1 \mathrm{H}, \mathrm{d}, \mathrm{H}^{10}{ }_{\mathrm{m}}\right), 7.33\left(1 \mathrm{H}, \mathrm{d}, \mathrm{H}^{3}{ }_{\mathrm{M}}\right), 7.06-6.99$ and $6.89\left(\mathrm{~m}, \mathrm{H}^{14,16,18}{ }_{\mathrm{M}, \mathrm{m}}\right), 6.84(1 \mathrm{H}, \mathrm{d}$, $\left.\mathrm{H}^{10}{ }_{\mathrm{M}}\right), 6.81\left(1 \mathrm{H}, \mathrm{d}, \mathrm{H}_{\mathrm{m}}^{3}\right), 6.63\left(2 \mathrm{H}, \mathrm{s}, \mathrm{H}^{14^{\prime}, 18^{\prime}}{ }_{\mathrm{m}}\right), 6.48\left(2 \mathrm{H}, \mathrm{s}, \mathrm{H}^{14^{\prime}, 18^{\prime}}{ }_{\mathrm{M}}\right), 3.90,3.88,3.85(\mathrm{~s}$, ${ }^{p} \mathrm{OCH}_{3, \mathrm{M}, \mathrm{m}}$ and $\left.^{\mathrm{m}} \mathrm{OCH}_{3, \mathrm{M}, \mathrm{m}}\right), 2.20\left(3 \mathrm{H}, \mathrm{s}, \mathrm{Pd}-\mathrm{NCCH}_{3, \mathrm{M}}\right), 2.17$ (3H, s, Pd-NCCH $\left.3, \mathrm{~m}\right), 1.00$ (3H, s, Pd$\left.\mathrm{CH}_{3, \mathrm{M}}\right), 0.87$ (3H, s, Pd-CH $\left.3, \mathrm{~m}\right)$.

Elemental analysis: C, 47.05; H, 3.42; N, 5.49. Found: C, 46.98; H, 3.44; N, 5.35.

[Pd( $\left.\left.\mathbf{C} \mathbf{H}_{3}\right)\left(\mathbf{C H}_{3} \mathbf{C N}\right)(7)\right]\left[\mathbf{P F}_{6}\right](\mathbf{7 b})$ Yield: $72 \%$. Yellow solid.

$\delta_{\mathrm{H}}\left(500 \mathrm{MHz} ; \mathrm{CD}_{2} \mathrm{Cl}_{2}\right) 8.26\left(2 \mathrm{H}, \mathrm{t}, \mathrm{H}^{5,8}\right), 7.65\left(2 \mathrm{H}, \mathrm{dt}, \mathrm{H}^{4,9}\right), 7.37\left(1 \mathrm{H}, \mathrm{d}, \mathrm{H}^{3}\right), 7.05-6.90(6 \mathrm{H}, \mathrm{m}$,

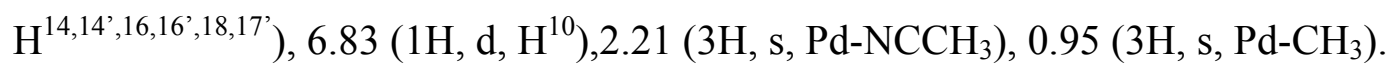

Elemental analysis: C, 45.56; H, 2.55; N, 5.90.Found: C, 45.44; H, 2.45; N, 5.85.

Reactivity studies.- Isolation of intermediates of the copolymerization reaction.

[Pd(COCH $\mathbf{3})(\mathbf{C I})(\mathbf{1})]$ (1c) Yield: $92 \%$. Dark green solid.

Compound 1a (100 mg, $0.153 \mathrm{mmol})$ was dissolved at $-20{ }^{\circ} \mathrm{C}$ under $\mathrm{CO}$ atmosphere in $2.5 \mathrm{~mL}$ of dichloromethane previously saturated with $\mathrm{CO}$. The solution was slowly warmed to $25{ }^{\circ} \mathrm{C}$, stirred for $1 \mathrm{~h}$, and then filtered through celite to remove traces of metallic Pd. A dark-green solid was 
obtained after evaporation of the solvent under vacuum which was washed with hexane $(3 \times 5 \mathrm{~mL})$ and dried, yielding compound 1c (96 mg, $0.141 \mathrm{mmol}, 92 \%)$.

$\delta_{\mathrm{H}}\left(200 \mathrm{MHz}, \mathrm{CD}_{2} \mathrm{Cl}_{2}, 298 \mathrm{~K}\right) 8.17\left(2 \mathrm{H}, \mathrm{dd}, \mathrm{H}^{5,8}\right), 7.98\left(1 \mathrm{H}, \mathrm{s}, \mathrm{H}^{16}\right), 7.87\left(2 \mathrm{H}, \mathrm{s}, \mathrm{H}^{14,18}\right), 7.55(2 \mathrm{H}$, $\left.\mathrm{dt}, \mathrm{H}^{4,9}\right), 7.14\left(2 \mathrm{H}, \mathrm{m}, \mathrm{H}^{16^{\prime}}\right.$ and $\left.\mathrm{H}^{3}\right), 6.93\left(\mathrm{~s}, 3 \mathrm{H}, \mathrm{H}^{14^{\prime}, 18^{\prime}}\right.$ and $\left.\mathrm{H}^{10}\right), 2.43\left(6 \mathrm{H}, \mathrm{s},-\left(\mathrm{CH}_{3}\right)_{2}-\mathrm{Ar}\right), 2.24(3 \mathrm{H}$, s, $\left.\mathrm{CH}_{3}-\mathrm{CO}\right) . \delta_{13 \mathrm{C}}\left(50.33 \mathrm{MHz}, \mathrm{CD}_{2} \mathrm{Cl}_{2}, 298 \mathrm{~K}\right) 220.26$ (CO-Pd), 144.61 (s, ipso-C-Ph-CF $), 140.00$ (s, ipso-C-Ph-CH $\left.{ }_{3}\right), 132.17,131.34\left(\mathrm{~s}, \mathrm{CH}^{5,8}\right), 129.40\left(\mathrm{~s}, \mathrm{CH}^{16}\right), 128.97,128.45\left(\mathrm{~s}, \mathrm{CH}^{4,9}\right), 126.08$ $\left(\mathrm{s}, C \mathrm{H}^{3}\right), 125.21\left(\mathrm{~s}, \mathrm{CH}^{10}\right), 122.33\left(\mathrm{~s}, C \mathrm{H}^{14,18}\right), 120.95\left(\mathrm{~s}, \mathrm{CH}^{16^{\prime}}\right), 117.98\left(\mathrm{~s}, C^{14^{\prime}, 18^{\prime}}\right), 32.65(\mathrm{~s}$, $\left.\mathrm{CH}_{3} \mathrm{CO}\right), 21.11$ (s, $\left.\mathrm{CH}_{3}-\mathrm{Ar}\right)$.

[Pd(CH3)(CO)(1)][BArF] (1d)Yield: $91 \%$. Red solid.

Compound 1c (90 mg, $0.132 \mathrm{mmol})$ was reacted with $\mathrm{Na}[\mathrm{BArF}](117 \mathrm{mg}, 0.132 \mathrm{mmol})$ at $-40{ }^{\circ} \mathrm{C}$ in $2.5 \mathrm{~mL}$ of dichloromethane. The reaction mixture was slowly warmed to $0{ }^{\circ} \mathrm{C}$, and the solution was filtered through celite to remove $\mathrm{NaCl}$. Then solvent was evaporated in vacuum, and the resulting solid was washed with hexane $(3 \times 5 \mathrm{~mL})$. A $182.38 \mathrm{mg}$ sample of the red compound $\mathbf{1 d}(0.121$ mmol, 91\%) was collected.

$\delta_{\mathrm{H}}\left(200 \mathrm{MHz}, \mathrm{CD}_{2} \mathrm{Cl}_{2}, 298 \mathrm{~K}\right) 8.25\left(2 \mathrm{H}, \mathrm{dd}, \mathrm{H}^{5,8}\right), 8.01\left(1 \mathrm{H}, \mathrm{s}, \mathrm{H}^{16}\right), 7.75\left(10 \mathrm{H}, \mathrm{brs}, \mathrm{H}^{14,18}, \mathrm{Ar}^{\prime}-\right.$ Ho), $7.57\left(6 \mathrm{H}, \mathrm{dt}, \mathrm{H}^{4,9}, \mathrm{Ar}^{\prime}-\mathrm{Hp}\right), 7.28\left(2 \mathrm{H}\right.$, br s, $\mathrm{H}^{16^{\prime}}$ and $\left.\mathrm{H}^{3}\right), 7.08\left(2 \mathrm{H}, \mathrm{brs}, \mathrm{H}^{14^{\prime}, 18^{\prime}}\right), 6.64(1 \mathrm{H}, \mathrm{s}$, $\left.\mathrm{H}^{10}\right), 2.46\left(6 \mathrm{H}, \mathrm{s},-\left(\mathrm{CH}_{3}\right)_{2}-\mathrm{Ar}\right), 1.31$ (3H, s, $\mathrm{CH}_{3}-\mathrm{Pd}$, major-trans), 1.07 (3H,s, $\mathrm{CH}_{3}-\mathrm{Pd}$, minor-cis). $\delta_{13 \mathrm{C}}\left(50.33 \mathrm{MHz}, \mathrm{CD}_{2} \mathrm{Cl}_{2}, 298 \mathrm{~K}\right) 174.38$ (s, CO-Pd, trans), 172.77 (s, CO-Pd, cis), $161.73\left(\mathrm{q},{ }^{1} J_{\mathrm{CB}}=\right.$ 49.8 Hz, Ar'-Cipso), 147.57, 147.27 (s, C=N), 141.26 (s, ipso-C-Ph-CH $)_{3}$, 141.04 (s, ipso-C-Ph$\left.\mathrm{CF}_{3}\right), 134.71\left(\mathrm{~s}, \mathrm{Ar}^{\prime}-\mathrm{Co}\right), 134.20\left(\mathrm{~s}, \mathrm{CH}^{5,8}\right), 133.71\left(\mathrm{~s}, \mathrm{CH}^{16^{\prime}}\right), 128.70\left(\mathrm{q},{ }^{2} J_{\mathrm{CF}}=28.33 \mathrm{~Hz}, \mathrm{Cm}-\mathrm{Ar}^{\prime}\right)$, $126.35\left(\mathrm{~s}, \mathrm{CH}^{4,9}\right), 124.84\left(\mathrm{q},{ }^{1} J_{\mathrm{CF}}=272.28 \mathrm{~Hz}, C \mathrm{~F}_{3}\right), 124.05,123.26\left(\mathrm{~s}, C^{14,18}\right), 121.78\left(\mathrm{~s}, C^{10}{ }^{10}\right)$, $121.43\left(\mathrm{~s}, \mathrm{CH}^{16}\right), 117.95\left(\mathrm{~s}, \mathrm{CH}^{14^{\prime}, 18^{\prime}}\right), 117.50\left(\mathrm{~s}, \mathrm{Ar}^{\prime}-\mathrm{Cp}\right), 21.29$ (s, $\left.\mathrm{CH}_{3}-\mathrm{Ph}\right), 12.09$ (s, $\mathrm{CH}_{3}-\mathrm{Pd}$, trans), 9.11 (s, $\mathrm{CH}_{3}-\mathrm{Pd}$, cis).

[Pd(CH(p-CH $\left.\left.-\mathbf{P h}) \mathrm{CH}_{2} \mathbf{C}(\mathbf{O}) \mathbf{C H}_{3}\right)(\mathbf{1})\right][\mathrm{BArF}](\mathbf{1 e})$ Yield: $83 \%$. Dark red solid.

p-Methylstyrene (13.00 $\mu \mathrm{L}, 0.1 \mathrm{mmol})$ was added to a solution of $\mathbf{1 d}(150 \mathrm{mg}, 0.099 \mathrm{mmol})$ in 2.5 $\mathrm{mL}$ of dichloromethane cooled to $-20{ }^{\circ} \mathrm{C}$. After $20 \mathrm{~min}$ the solvent was evaporated in a vacuum, and the resulting solid was washed with hexane $(2 \times 4 \mathrm{~mL})$. A $132.46 \mathrm{mg}$ sample of the dark-red compound $1 \mathbf{e}(0.083 \mathrm{mmol}, 83 \%)$ was collected.This complex is stable in solution only for a few hours.

$\delta_{\mathrm{H}}\left(200 \mathrm{MHz}, \mathrm{CD}_{2} \mathrm{Cl}_{2}, 298 \mathrm{~K}\right) 8.13\left(2 \mathrm{H}, \mathrm{dd}, \mathrm{H}^{5,8}\right), 8.11\left(3 \mathrm{H}, \mathrm{m}, \mathrm{H}^{16}\right.$ and $\left.\mathrm{H}^{14,18}\right), 7.74\left(8 \mathrm{H}, \mathrm{s}, \mathrm{Ar}^{\prime}-\right.$ Ho), $7.56\left(6 \mathrm{H}, \mathrm{s}, \mathrm{H}^{4,9}\right.$ and $\left.\mathrm{Ar}^{\prime}-\mathrm{Hp}\right), 7.24\left(2 \mathrm{H}, \mathrm{m}, \mathrm{H}^{16^{\prime}}\right.$ and $\left.\mathrm{H}^{3}\right), 6.97\left(2 \mathrm{H}, \mathrm{s}, \mathrm{H}^{14^{\prime}, 18^{\prime}}\right), 6.88(2 \mathrm{H}, \mathrm{m}$, CHo-Ph), $6.59\left(1 \mathrm{H}, \mathrm{s}, \mathrm{H}^{10}\right), 6.55$ (2H, s, CHm-Ph), 3.51 (1H, dd, CHa), $2.87(1 \mathrm{H}, \mathrm{d}, \mathrm{CHb}), 2.47$ $\left(6 \mathrm{H}, \mathrm{s},-\left(\mathrm{CH}_{3}\right)_{2}-\mathrm{Ar}\right), 2.10\left(3 \mathrm{H}, \mathrm{s}, \mathrm{CH}_{3}(\mathrm{CO})\right), 1.98\left(1 \mathrm{H}, \mathrm{d}, \mathrm{CHb}^{\prime}\right), 1.89\left(3 \mathrm{H}, \mathrm{s}, \mathrm{CH}_{3}-\mathrm{Ph}\right)$. 
Bubbling $\mathrm{CO}$ at $-30{ }^{\circ} \mathrm{C}$ for $10 \mathrm{~min}$ into a $\mathrm{CD}_{2} \mathrm{Cl}_{2}$ solution $(0.6 \mathrm{~mL})$ of $1 \mathrm{e}(60 \mathrm{mg})$ resulted in the formation of $\mathbf{1 f}$. This complex is stable in solution only for a few hours.

$\delta_{\mathrm{H}}\left(200 \mathrm{MHz}, \mathrm{CD}_{2} \mathrm{Cl}_{2}, 250.9 \mathrm{~K}\right) 8.16\left(2 \mathrm{H}, \mathrm{dd}, \mathrm{H}^{5,8}\right), 8.10\left(1 \mathrm{H}, \mathrm{s}, \mathrm{H}^{16}\right), 7.87\left(2 \mathrm{H}, \mathrm{s}, \mathrm{H}^{14,18}\right), 7.77(8 \mathrm{H}$, s, Ar'-Ho), $7.64\left(2 \mathrm{H}, \mathrm{dt}, \mathrm{H}^{4,9}\right), 7.56\left(\mathrm{~s}, 4 \mathrm{H}, \mathrm{Ar}^{\prime}-\mathrm{Hp}\right), 7.23\left(2 \mathrm{H}, \mathrm{m}, \mathrm{H}^{16^{\prime}}\right.$ and $\left.\mathrm{H}^{3}\right), 7.18(4 \mathrm{H}, \mathrm{m}, \mathrm{CH}-$ $\mathrm{Ph}), 6.95\left(2 \mathrm{H}, \mathrm{s}, \mathrm{H}^{14^{\prime}, 18^{\prime}}\right), 6.86\left(1 \mathrm{H}, \mathrm{s}, \mathrm{H}^{10}\right), 4.64(1 \mathrm{H}, \mathrm{t}, \mathrm{CHa}), 2.81(1 \mathrm{H}, \mathrm{d}, \mathrm{CHb}), 2.76(\mathrm{~d}, 1 \mathrm{H}$, $\left.\mathrm{CHb}^{\prime}\right), 2.36\left(3 \mathrm{H}, \mathrm{s}, \mathrm{CH}_{3}-\mathrm{Ph}\right), 2.27,2.13\left(6 \mathrm{H}, \mathrm{s},-\left(\mathrm{CH}_{3}\right)_{2}-\mathrm{Ar}\right) 1.96\left(3 \mathrm{H}, \mathrm{s}, \mathrm{CH}_{3}(\mathrm{CO})\right)$.

\section{$\left[\mathrm{Pd}\left(\mathrm{C}(\mathrm{O})\left(\mathrm{CH}\left(p-\mathrm{CH}_{3}-\mathrm{Ph}\right) \mathrm{CH}_{2}\right)_{2} \mathrm{C}(\mathrm{O}) \mathrm{CH}_{3}\right)(\mathrm{CO})(1)\right]\left[\mathrm{BAr}_{4}{ }_{4}\right](1 \mathrm{~g})$}

p-Methylstyrene $(4.3 \mu \mathrm{L}, 0.1 \mathrm{mmol})$ was added into a $\mathrm{CD}_{2} \mathrm{Cl}_{2}$ solution $(0.6 \mathrm{~mL})$ of $\mathbf{1 f}(50 \mathrm{mg}, 0.033$ mmol) cooled to $-30{ }^{\circ} \mathrm{C}$. The solution was left for $16 \mathrm{~h}$ at $-18{ }^{\circ} \mathrm{C}$ to yield compound $1 \mathrm{~g}$. This complex is stable in solution only for a few hours.

$\delta_{\mathrm{H}}\left(200 \mathrm{MHz}, \mathrm{CD}_{2} \mathrm{Cl}_{2}, 243 \mathrm{~K}\right) 8.13\left(2 \mathrm{H}, \mathrm{dd}, \mathrm{H}^{5,8}\right), 7.89\left(3 \mathrm{H}\right.$, brs, $\left.\mathrm{H}^{14,16,18}\right), 7.78\left(10 \mathrm{H}\right.$, brs, H, $\mathrm{H}^{4,9}, \mathrm{Ar}^{\prime}-$ Ho), 7.49 (4H, s, Ar'-Hp), 7.49-7.41 (2H, m, H${ }^{16^{\prime}}$ and $\left.\mathrm{H}^{3}\right), 7.30-6.85\left(11 \mathrm{H}, \mathrm{m}, \mathrm{CH}-\mathrm{Ph}, \mathrm{H}^{14^{\prime}, 18^{\prime}}, \mathrm{H}^{10}\right)$, 4.25-3.75 (2H, m, CHc and $\mathrm{CHd}), 3.50-3.10(2 \mathrm{H}, \mathrm{m}, \mathrm{CHa}$ and $\mathrm{CHe}), 2.80-2.50(2 \mathrm{H}, \mathrm{m}, \mathrm{CHb}$ and CHf), 2.50-2.00 (9H, m, - $\left.\left(\mathrm{CH}_{3}\right)_{2}-\mathrm{Ar}, \mathrm{CH}_{3}-\mathrm{Ph}\right), 1.84\left(3 \mathrm{H}, \mathrm{s}, \mathrm{CH}_{3}(\mathrm{CO})\right)$.

CO/vinyl arenes copolymerizationreactions at 3 - 10 bar. Catalytic experiments were performed simultaneously in the parallel autoclave system AMTEC SPR16, equipped with pressure sensors and a mass-flow controller suitable for monitoring and recording gas uptakes throughout the reactions. Four stainless steel autoclaves $(12 \mathrm{~mL})$ of the AMTEC SPR16 were flushed with argon. A solution of the Pd catalyst and 1,4-benzoquinone in trifluoroethanol $(20 \mathrm{~mL})$ was prepared and the reactors were charged each with $5 \mathrm{~mL}$ of the catalyst solution as well as $3 \mathrm{~mL}$ of the alkene comonomer. The atmosphere was exchanged with carbon monoxide (gas exchange cycle 1) and the reactors were pressurized to the desired value. After heating to the desired temperature $\left(30^{\circ} \mathrm{C}\right)$, the final pressures were adjusted and kept constant throughout the experiment. The carbon monoxide uptake was monitored and recorded automatically.

\section{X-ray crystallography}

Collection data of 1a and 3a were carried out at room temperature on a Nonius DIP-1030H system equipped with Mo-K $\alpha$ radiation $(\lambda=0.71073 \AA)$. Cell refinement, indexing and scaling of the data sets were carried out using Denzo ${ }^{70}$ and Scalepack. ${ }^{70}$ The structures were solved by direct methods and subsequent Fourier analyses ${ }^{71}$ and refined by the full-matrix least-squares method based on $F^{2}$ with all observed reflections. ${ }^{71}$ All the calculations were performed using the WinGX System, Ver $1.80 .05 .^{72}$ 
Table 6. Crystallographic data for compounds1a and 3a.

\begin{tabular}{|l|l|l|}
\hline & 1a & 3a \\
\hline Empirical formula & $\mathrm{C}_{29} \mathrm{H}_{21} \mathrm{ClF}_{6} \mathrm{~N}_{2} \mathrm{Pd}$ & $\mathrm{C}_{28} \mathrm{H}_{23} \mathrm{ClF}_{2} \mathrm{~N}_{2} \mathrm{O}_{3} \mathrm{Pd}$ \\
\hline fw & 653.33 & 615.33 \\
\hline Crystal system & Monoclinic & Monoclinic \\
\hline Space group & $P 2{ }_{1} / \mathrm{c}$ & $\mathrm{P} 2{ }_{1} / \mathrm{c}$ \\
\hline$a, \AA$ & $12.138(4)$ & $14.707(4)$ \\
\hline$b, \AA$ & $24.329(5)$ & $14.627(3)$ \\
\hline$c, \AA$ & $8.973(4)$ & $12.192(3)$ \\
\hline$\beta$, deg & $94.82(4)$ & $103.82(3)$ \\
\hline$V, \AA^{3}$ & $2640.4(16)$ & $2546.8(11)$ \\
\hline$Z$ & 4 & 4 \\
\hline$D$ calcd, g cm & 1.644 & 1.605 \\
\hline$\mu($ Mo-K $\alpha), \mathrm{mm}^{-1}$ & 0.868 & 0.882 \\
\hline$F(000)$ & 1304 & 1240 \\
\hline$\theta$ range, deg & $1.67-27.10$ & $1.43-27.05$ \\
\hline no. of reflnscollcd & 28892 & 29141 \\
\hline no. of indepreflns & 5799 & 5547 \\
\hline$R$ Rint & 0.1192 & 0.0870 \\
\hline no. of reflns $(I>2 \sigma(I))$ & 2762 & 2614 \\
\hline no. of refined params & 353 & 334 \\
\hline goodness-of-fit $\left(F^{2}\right)$ & 0.916 & 0.901 \\
\hline$R 1, w R 2(I>2 \sigma(I))^{[a]}$ & $0.0647,0.1449$ & $0.0463,0.0928$ \\
\hline residuals, e/ $\AA^{3}$ & $0.793,-0.665$ & $0.486,-0.463$ \\
\hline
\end{tabular}

${ }^{[\mathrm{a}]} R 1=\Sigma|| F_{\mathrm{O}}|-| F_{\mathrm{C}}|| / \Sigma\left|F_{\mathrm{O}}\right|, w R 2=\left[\Sigma w\left(F_{\mathrm{O}}^{2}-F_{\mathrm{c}}{ }^{2}\right)^{2} / \Sigma w\left(F_{\mathrm{O}}{ }^{2}\right)^{2}\right]^{1 / 2}$

\section{Acknowledgements}

Collaborative research was carried out by D.V. and B.M. in the framework of the COST D40 project of the EC that is also acknowledged for the financial support of an STSM of F.A. to Eindhoven University of Technology. This work was supported by MIUR (PRIN N²007HMTJWP_002;PRIN $\mathrm{N}^{\circ}$ 2008A7P7YJ_003).We thank Dr. F. Ferretti and A. Caselli for help in the synthesis and characterization of ligands 3 and 7 and Dr. P. Natanti for characterization of complexes 1a-1g. Engelhard Italia is gratefully acknowledged for a generous gift of $\left[\operatorname{Pd}(\mathrm{AcO})_{2}\right]$. Fondazione CRTrieste is also gratefully acknowledged for the generous donation to the Dipartimento di Scienze Chimiche e Farmaceutiche of a Varian 500 NMR spectrometer. 


\section{References}

I. Matei and T. Lixandru, Chem. Abstr., 1969, 70, 3623.

R. Van Asselt and C. J. Elsevier, Organometallics, 1992, 11, 1999.

L. K. Johnson, C. M. Killian, and M. Brookhart, J. Am. Chem. Soc., 1995, 117, 6414.

S. D. Ittel, L. K. Johnson, and M. Brookhart, Chem. Rev., 2000, 100, 1169.

L. K. Johnson, S. Mecking, and M. Brookhart, J. Am. Chem. Soc., 1996, 118, 267.

S. Mecking, L. K. Johnson, L. Wang, and M. Brookhart, J. Am. Chem. Soc., 1998, 120, 888.

A. Nakamura, S. Ito, and K. Nozaki, Chem. Rev., 2009, 109, 5215.

D. Pappalardo, M. Mazzeo, S. Antinucci, and C. Pellecchia, Macromolecules, 2000, 33, 9483.

J. Kiesewetter and W. Kaminsky, Chem. Eur. J., 2003, 9, 1750.

C. S. Popeney, D. H. Camacho, and Z. Guan, J. Am. Chem. Soc., 2007, 129, 10062.

L. Guo, H. Gao, Q. Guan, H. Hu, J. Deng, J. Liu, F. Liu, and Q. Wu, Organometallics, 2012, 31, 6054.

R. van Asselt, E. E. C. G. Gielens, R. E. Rülke, and C. J. Elsevier, J. Chem. Soc. Chem. Commun., 1993, 1203.

G. Bellachioma, B. Binotti, G. Cardaci, C. Carfagna, A. Macchioni, S. Sabatini, and C. Zuccaccia, Inorg. Chim. Acta, 2002, 330, 44.

B. Binotti, C. Carfagna, C. Zuccaccia, and A. Macchioni, Chem. Commun., 2005, 92.

B. Binotti, G. Bellachioma, G. Cardaci, C. Carfagna, C. Zuccaccia, and A. Macchioni, Chem. Eur. J., 2007, 13, 1570.

M. Gasperini, F. Ragaini, E. Gazzola, A. Caselli, and P. Macchi, Dalton Trans., 2004, 3376.

A. Scarel, M. R. Axet, F. Amoroso, F. Ragaini, C. J. Elsevier, A. Holuigue, C. Carfagna, L. Mosca, and B. Milani, Organometallics, 2008, 27, 1486.

A. Meduri, T. Montini, F. Ragaini, P. Fornasiero, E. Zangrando, and B. Milani, ChemCatChem, 2013, 5, 1170 .

R. Van Asselt, C. J. Elsevier, W. J. J. Smeets, A. L. Spek, and R. Benedix, Recl. Trav. Chim. Pays-Bas, 1994, 113, 88.

M. Gasperini, F. Ragaini, and S. Cenini, Organometallics, 2002, 21, 2950.

J. Durand, E. Zangrando, M. Stener, G. Fronzoni, C. Carfagna, B. Binotti, P. C. J. Kamer, C. Muller, M. Caporali, P. W. N. M. van Leeuwen, D. Vogt, and B. Milani, Chem. Eur. J., 2006, 12, 7639.

F. Ragaini, M. Gasperini, P. Parma, E. Gallo, N. Casati, and P. Macchi, New J. Chem., 2006, 30, 1046.

M. Hagar, F. Ragaini, E. Monticelli, A. Caselli, P. Macchi, and N. Casati, Chem. Commun., 2010, 46, 6153.

J. Zhou, H. Sun, K. Harms, and J. Sundermeyer, Z. Anorg. Allg. Chem., 2008, 634, 1517.

A. Bastero, A. Ruiz, C. Claver, B. Milani, and E. Zangrando, Organometallics, 2002, 21, 5820.

A. Scarel, J. Durand, D. Franchi, E. Zangrando, G. Mestroni, B. Milani, S. Gladiali, C. Carfagna, B. Binotti, S. Bronco, and T. Gragnoli, J. Organomet. Chem., 2005, 690, 2106.

M. R. Axet, F. Amoroso, G. Bottari, A. D'Amora, E. Zangrando, F. Faraone, D. Drommi, M. Saporita, C. Carfagna, P. Natanti, R. Seraglia, and B. Milani, Organometallics, 2009, 28, 4464.

A. Bastero, C. Claver, A. Ruiz, S. Castillon, E. Daura, C. Bo, and E. Zangrando, Chem. Eur. J., 2004, 10, 3747.

A. D'Amora, L. Fanfoni, D. Cozzula, N. Guidolin, E. Zangrando, F. Felluga, S. Gladiali, F. Benedetti, and B. Milani, Organometallics, 2010, 29, 4472.

J. March, 'Advanced organic chemistry', John Wiley \& Sons, Inc., 1992.

C. Besson, E. E. Finney, and R. G. Finke, J. Am. Chem. Soc., 2005, 127, 8179.

M. A. Watzky and R. G. Finke, J. Am. Chem. Soc., 1997, 119, 10382.

P. H. M. Budzelaar, P. W. N. M. Van Leeuwen, C. F. Roobeek, and A. G. Orpen, Organometallics, 1992, 11, 23.

M. Tromp, J. R. A. Sietsma, J. A. van Bokhoven, G. P. F. van Strijdonck, R. J. van Haaren, A. M. J. van der Eerden, P. W. N. M. van Leeuwen, and D. C. Koningsberger, Chem. Commun., 2003, 128. M. Portnoy, F. Frolow, and D. Milstein, Organometallics, 1991, 10, 3960. 
F. Ragaini, H. Larici, M. Rimoldi, A. Caselli, F. Ferretti, P. Macchi, and N. Casati, Organometallics, 2011, 30, 2385.

The possibility that the irreversible step of the decomposition is the reaction of two palladium(0) complexes should also be considered. However, palladium(0) complex concentrations should be very low at any moment and this process is quite unlikely to play a relevant role in the present system. From a kinetic point of view, a process of this kind would be distinguishable from that in path $B$ only if the concentration/time profile for benzoquinone were also known, which is not the case, and so we will ignore it in the following.

M. Gasperini and F. Ragaini, Organometallics, 2004, 23, 995.

Note that the same "volume" amount of the two olefins was employed. Given the higher MW and molar volume of the methyl-substituted substrate, the molar concentration of the latter was actually a little lower than that of styrene during the reactions. However, the reactivity difference is much larger than that attributable to such a small dilution effect and must have a different origin.

M. Brookhart, M. I. Wagner, G. G. A. Balavoine, and H. A. Haddou, J. Am. Chem. Soc., 1994, 116, 3641.

S. Bartolini, C. Carfagna, and A. Musco, Macromol. Rapid Commun., 1995, 16, 9.

C. Carfagna, G. Gatti, D. Martini, and C. Pettinari, Organometallics, 2001, 20, 2175.

A. Scarel, B. Milani, E. Zangrando, M. Stener, S. Furlan, G. Fronzoni, G. Mestroni, S. Gladiali, C. Carfagna, and L. Mosca, Organometallics, 2004, 23, 5593.

The experiment at 10 bar with 3,5-(CH3)2C6 $33^{\cdots \cdots \cdots} ; 3,5-(\mathrm{CF} 3) 2 \mathrm{C} 6 \mathrm{H} 3-\mathrm{BIAN}$ was also performed. It is not included in the discussion because the data are of poor quality. However, even if quantitative data are inaccurate, the reaction rate was without doubt slower than that of both the reactions run under 3 and 5 bar with the same ligand.

B. Milani, G. Corso, G. Mestroni, C. Carfagna, M. Formica, and R. Seraglia, Organometallics, 2000, 19, 3435.

M. Sperrle, A. Aeby, G. Consiglio, and A. Pfaltz, Helv. Chim. Acta, 1996, 79, 1387.

W. P. Mul, A. W. van der Made, A. A. Samaardijk, and E. Drent, in 'Catalytic synthesis of copolymers and terpolymers', ed. A. Sen, Dordrecht, 2003.

A. Gsponer, T. M. Schmid, and G. Consiglio, Helv. Chim. Acta, 2001, 84, 2986.

J. Durand, A. Scarel, B. Milani, R. Seraglia, S. Gladiali, C. Carfagna, and B. Binotti, Helv. Chim. Acta, 2006, 89, 1752.

D. P. Gates, S. A. Svejda, E. Onate, C. M. Killian, L. K. Johnson, P. S. White, and M. Brookhart, Macromolecules, 2000, 33, 2320.

M. P. Weberski, C. Chen, M. Delferro, C. Zuccaccia, A. Macchioni, and T. J. Marks, Organometallics, 2012, 31, 3773.

H. Grennberg, A. Gogoll, and J. E. Baeckvall, Organometallics, 1993, 12, 1790.

R. A. Klein, C. J. Elsevier, and F. e. Hartl, Organometallics, 1997, 16, 1284.

R. A. Klein, P. Witte, R. van Belzen, J. Fraanje, K. Goubitz, M. Numan, H. Schenk, J. M. Ernsting, and C. J. Elsevier, Eur. J. Inorg. Chem., 1998, 319.

B. Milani, A. Anzilutti, L. Vicentini, A. Sessanta o Santi, E. Zangrando, S. Geremia, and G. Mestroni, Organometallics, 1997, 16, 5064.

E. Drent and P. H. M. Budzelaar, Chem. Rev., 1996, 96, 663.

K. J. Cavell, D. J. Stufkens, and K. Vrieze, Inorg, Chim. Acta, 1981, 47, 67.

A. M. Kluwer, C. J. Elsevier, M. Bühl, M. Lutz, and A. L. Spek, Angew. Chem. Intern. Ed., 2003, 42, 3501.

B. V. Popp, J. L. Thorman, C. M. Morales, C. R. Landis, and S. S. Stahl, J. Am. Chem. Soc., 2004, 126, 14832.

M. Brookhart, F. C. Rix, J. M. DeSimone, and J. C. Barborak, J. Am. Chem. Soc., 1992, 114, 5894.

B. Binotti, C. Carfagna, G. Gatti, D. Martini, L. Mosca, and C. Pettinari, Organometallics, 2003, 22, 1115.

C. Carfagna, G. Gatti, L. Mosca, A. Passeri, P. Paoli, and A. Guerri, Chem. Commun., 2007, 4540.

K. Nozaki, H. Komaki, Y. Kawashima, T. Hiyama, and T. Matsubara, J. Am. Chem. Soc., 2001, 123, 534. 
B. Milani, F. Paronetto, and E. Zangrando, J. Chem. Soc. , Dalton Trans., 2000, 3055.

J. A. Iggo, Y. Kawashima, J. Liu, T. Hiyama, and K. Nozaki, Organometallics, 2003, 22, 5418.

L. Resconi, L. Cavallo, A. Fait, and F. Piemontesi, Chem. Rev., 2000, 100, 1253.

K. Nozaki, N. Sato, Y. Tonomura, M. Yasutomi, H. Takaya, T. Hijama, T. Matsubara, and N. Koga, J. Am. Chem. Soc., 1997, 119, 12779.

D. Guironnet, L. Caporaso, B. Neuwald, I. Gottker-Schnetmann, L. Cavallo, and S. Mecking, J. Am. Chem. Soc., 2010, 132, 4418.

S. Noda, A. Nakamura, T. Kochi, L. W. Chung, K. Morokuma, and K. Nozaki, J. Am. Chem. Soc., 2009, $131,14088$.

Z. Otwinowski and W. Minor, in 'Macromolecular Crystallography, part A', ed. C.W. Carter Jr and R. M. Sweet, New York, 1197.

G. M. Sheldrick, Acta Cryst., 2008, A64, 112.

L. J. Farrugia, J. Appl. Crystallogr., 1999, 32, 837. 


\section{Table of Content}

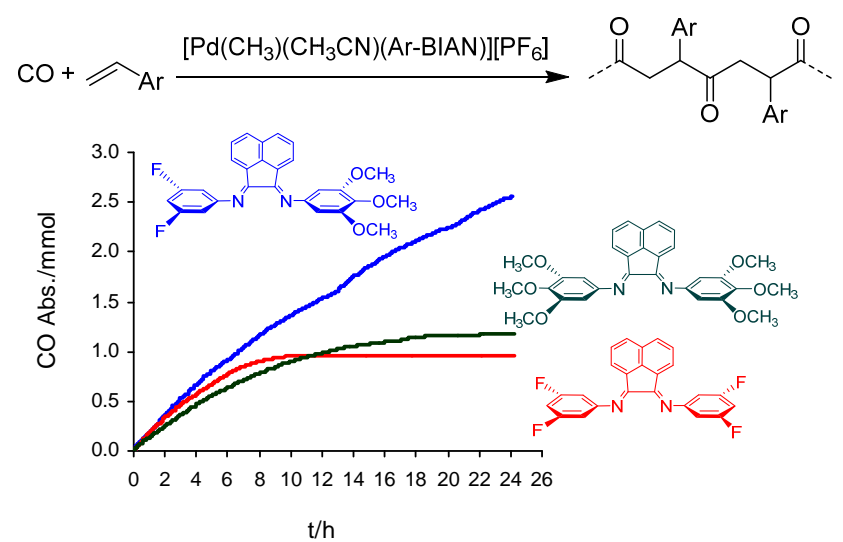

Palladium catalysts having nonsymmetrical $\alpha$-diimines show, in the CO/vinyl arene copolymerization, better performance than those with the corresponding symmetric ligands. The reasons for this behavior have been investigated by kinetic methods, modelization, and mechanistic studies. 